[Aus dem pathologiseh-anatomischen Institut der Universität Kiew.

(Vorstand: Prof. W. v. Wyssokowitsch.)]

\title{
Iridochorioiditis serosa nach langjährigem Verweilen eines Eisensplitters im Ange, zugleich ein Beitrag zur Siderosis bulbi.
}

\author{
Von \\ Dr. J. Rubert, \\ Privatdozenten in Kiew.
}

Mit Taf. XV u. XVI, Fig. 1-4.

Dringt ein nicht zu grosser Fremdkörper aseptisch ins Augenimnere ein, so kann dieser zunächst reaktionslos einheilen. Seine Wirkung bleibt aber nicht aus und hängt diese, wie die grundlegenden experimentellen Untersuchungen Lebers uns zuerst gezeigt haben, von der chemischen Beschaffenheit der eingedrungenen Substanz ab.

Die Versuche und Beobachtungen dieses Forschers über die Wirkung von Fremdkörpern aus Eisen lehren uns, dass die entzündungerregenden Eigenschaften dieses Metalles geringfügig sind, anderseits aber, dass letzteres schwere Veränderungen anderer Art hervorzurufen im stande ist, wenn dieses in den Glaskörperraum eingeführt wurde. Diese äusseru sich in Ablösung und Zerreissung der Netzhaut durch Glaskörperschrumpfung und in einer eigentümlichen Form von Atrophie der Netzhaut. Die Verbreitung des Eisens im Auge wird nach Leber zunächst durch die Kohlensäure der Gewebe bewirkt, welche das Eisen löst. Letzteres diffundiert dann als doppelt kohlensaures Eisenoxydul and wird nachher durch den vou den Arterien zugetuihrten Sauerstoff in unlöslicher Form in mehr oder minder grossem Abstande von dem Fremdkörper niedergeschlagen. Bunge, dem wir die ersten Untersuchungen über die Ausbreitung des Eisens im menschlichen Auge verdanken, hat die Imprägnation des Gewebes mit Eisenoxydsalzen als Siderosis bulbi bezeichnet und dieser Ausdruck hat sicb auch mit Recht eingebürgert. 
Iridochorioiditis serosa nach langjahr. Verweilen eines Eisensplitters usw. 269

Die am Tierauge erzielten Resultate haben durch spätere Forscher, besonders durch E. v. Hippel, auch am menschlichen Auge im allgemeinen ihre Bestätigung erfahren und sind hier die Erscheinungen und Folgen der Siderosis noch genauer erforscht worden. v. Hippel (18) kommt auf Grund wie seiner eigenen Beobachtungen, so auch derjenigen anderer zu bemerkenswertem Schluss, dass ein im hinteren Bulbusabschnitt lokalisierter Eisensplitter, auch wenn derselbe anfangs reizlos vertragen wird, das Ange immerhin Gefahren noch aussetzt. Diese können von viererlei Art sein: 1. Netzhautablösung, bedingt durch Schrumpfung des Glaskörpers; 2. Auftreten von Entzündung; 3. Erkrankung der Macula und 4. Netzhautdegeneration.

Trotz der grossen Häufigkeit, mit welcher Eisensplitterverletzungen dem Augenarzte begegnen, erweist sich doch die Zahl der genauer veröffentlichten pathologisch-anatomischen Befunde von Fällen, in welchen Eisenfragmente jahrelang im Augeninneren reizlos vertragen wurden und nachher Entziindung eintrat, als recht gering. Ungeachtet dessen sind wir doch über die Art der Ausbreitung des Eisens und über die infolge der Siderosis sich einstellenden degenerativen Veränderungen verhältnismässig gut unterrichtet, da die Befunde zu mehr oder weniger übereinstimmenden Resultaten geführt haben. Dagegen müussen unsere Kenntnisse über das anatomische Bild der später auftretenden Entzündung, und zu solcher soll es stets kommen [Schirmer(36)], als recht liickenhaft bezeichnet werden. Wurde ein Splitter vom Auge reizlos vertragen, so konnte ein solcher unter Umständen im Bulbusinneren vielleicht noch belassen werden, sobald aber die ersten Reizerscheinungen sich einstellten, so war seines ferneren Duldens natürlich nicht mehr am Platze und die Enucleation trat in ihre Rechte. Es muss uns daher verständlich erscheinen, warum in den meisten mikroskopisch untersuchten Fällen keine nennenswerten Entzïndungszeichen nachzuweisen waren oder diese überhaupt noch fehlten. In den Fällen, wo von mehr heftigen Entzündungserscheinungen berichtet wird, konute in einem gewissen Teil die Entzündung nicht auf den Fremdkörper als solchen zurückgeführt werden (20, 25, 32 u. A.), in einer andern Reihe ron Fällen erschienen die Angaben wieder recht ungenügend, um sie verwerten zu dürfen, solche Fälle sind gewöhnlich bei andern Gelegenheiten beschrieben und auch von anderm Standpunkte behandelt worden $(10,44$ u. A.).

Nach dem Gesagten glaube ich berechtigt zu sein, iiber einen Fall Mitteilung zu machen, wo nach ungefähr 12jährigem reizlosem. Verweilen eines Eisensplitters im Bulbusinneren eine Entzündung 
folgte. Diese rezidivierte häufig und erst nach mehr als tjährigem Verlaufe willigte der Patient in die Operation ein. Ein besonderes Interesse diufte der Fall noch deswegen beanspruchen, da das Leiden unter dem Bildo einer typischen Iridochorioiditis serosa verlief.

Auch bei dieser Krankheit hat die anatomische Forschung mit der klinischen nicht gleichen Schritt gehalten. Die in der Literatur vereinzeit stehenden pathologisch-anatomischen Befunde bei der serösen Uveitis beziehen sich fast ansschliesslich auf die idiopathische Form dieses Leidens (Schweigger, Knies, Panas, Ridley, Baas, Groenouw, Harms). Es ist schon längst bekannt, dass die Tridocyclitis serosa mitunter auch nach Trauma sich einzustellen pflegt, diese Fülle zeichnen sich aber im Gegensatze zu den vorigen durch die Gutartigkeit ihres Verlaufes aus.

Vor einigen Jahren vermochte uns Fuchs(8) über das pathologisch-anatomische Bild von drei einschlägigen Fällen zu berichten. Fuchs findet den Befund bei tramatischer seröser Iridocyclitis dem bei spoutaner ähnlich und stehe er im anatomischen Sinne auch dem bei sympathisierender Entzündung wahe. Als Unterschied zwischen der ersten und letzten Fntziundungsform hebt er das Freibleiben der Aderhant bei dex serösen Entzïndung hervor; während die sympathisierende gerade in der Aderhaut am stärksten zu sein pflegt, ferner das Fehleir ron epitheloiden und Riesenzellen imnerhalb der Gewebsinfiltration bei der serösen Entzündung. Das Gemeinsame der spontanen chronischen Entzündungen mit der sympathisierenden und der serösen trauma. tischen liegt nach Fuchs darin, dass sie alle infiltrierende Entzünlungen sind, während gewöhnlich nach einem perforierenden Trauma, welches eine Infektion des Augeninueren setzt, eine Entzïndung entsteht, an der vor allem die Membranen beteiligt sind, welche die inneren Augenräume auskleiden, also Iris, Ciliarkörper, Netzhaut, wobei es auf deren Oberfläche zu einer bald mehr fibrinösen, bald mehr eitrigen Exsudation kommt (Endophthalmitis septica). Bei der serösen Entzïndung fehlt die Exsudation an der Oberfläche total oder sie ist sehr geringen Grades.

Die mikroskopische Untersuchung meines Falles ergab eine äusserst chronische infiltrierende Entzündung im Simne Fuchs' des Urealtraktes, vornehmlich der Tris und der Chorioidea bei geringer Oberthächenexsudation. Zugleich lieferte die Untersuchung einen pathologisehmatomischen Beitrag zur Klärung einzelner wie bei der serösen Ureitis, so auch bei der Siderosis bulbi sich abspielender Vorgänge. Die Seltenheit und Mannigfaltigkeit des Befundes rechtfertigt eine aus- 
führliche Beschreibung. Ich beginne mit der Krankengeschichte meines Falles.

Am 20. IX. 1908 erschien in der hiesigen Augenambulanz des Roten Kreuzes der 45 jährige Schmied Samuel A. mit Klagen über starke Schmerzhaftigkeit des linken Auges und der entsprechenden Kopfhälfte. Vor 16 Jahren sei ihm ein Eisensplitter gegen das linke Auge geflogen. Während einer Woche hätte ihn ein Arzt mit Tropfen und Verband behandelt und nachtem als gesund entlassen. Nach diesem Vorfalle soll das Auge bedeutend schwächer gesehen haben als vorher. Im Laufe der nächsten Jahre wäre allmähliche Abnahme der Sehschärfe eingetreten und das Auge erblindet. Vor ungefảhr $41 / 2$ Jahren hätte letzteres zum erstenmal begonnen zu schmerzen und sich zu röten. Nachher sollen die Schmerzen mit Entziindungserscheinungen sich vielfach wiederholt haben. Ursprünglich seien die Anfälle von kürzerer Dauer und weniger intensiv gewesen, seit sechs Wochen tue ihm das Ange besonders weh. An einen Arzt hätte Patient im Laufe der 16 Jahre sich nicht gewendet und zur Not das Auge nur mit Hansmitieln behandelt.

Das linke Ange ist mässig pericorneal injiziert. Die Oberfläche der Hornhaut erscheint leicht uneben, das Epithel gestippt und matt. Auf der Hornhautrückfläche sieht man in ihrer unteren Hälfte zahlreiche punktförmige dunkelbraune Beschläge. Die Vorderkammer ist etwas seichter als rechts. Die Iris erscheint unregelmässig geschwollen, besonders in ihrem pupillaren Teil, das Relief verschwommen, der Glanz verändert. Die Farbe der Iris ist, wie rechts, dunkelbraun. Stellenweise sieht man auf der Oberfläche der Iris erweiterte Gefässe. Die Pupille ist verengt und durch eine bräunliche Membran verschlossen, die Iris ist am pupillaren Rande mit letzterer cirkulär verwachsen. $V=0, T 46 \mathrm{~mm} H g$ (Maklakoff). Das Auge ist auf Druck nicht besonders empfindlich. Strabismus divergens lev. gi: Die Motilität des Auges ist ungestört.

Das rechte Auge erscheint normal. $\quad F=1,0$. Striae medullares. Beiderseits leicht ausgesprochenes Narbentrachom am oberen Lide. Seitens des allgemeinen Zustandes liegt niehts Pathologisches vor, auch ist von irgendeiner konstitutionellen Affektion nichts zu sehen.

Auf die vorgeschlagene Enucleation ging Patient nicht ein und wurde mit der Anweisung, Kataplasmata zu machen und Tropfen ins Auge zn träufeln (Pilokarpin 0,06:10,0), entlassen. - Am 1. XI. stellte sich Patient wieder ein. Er behauptete, seit vier Wochen sich wohl zu fühlen. Das Auge war blass, die Hornhaut durchsichtig, die Beschläge der Descemetia waren fast völlig geschwunden, auch seitens der Regenbogenhaut konnten ausgesprochene entzündliche Erscheinungen nicht vermerkt werden. $T 32$. Am 3. III. 09 erschien Patient wieder in der Ambulanz. Nach Anssage des Patienten wären die Schmerzen seit zwei Wochen unerträglich geworden. Objektiv unterschied sich das Bild nicht von dem bei der erstmaligen Inspektion. Die Hornhautbeschläge waren vielleicht noch zahlreicher geworden und die Injektion erschien noch stärker ausgesprochen. $T$ 56. Patient willigte jetzt in die Operation ein. 4. III. Enucleation in Chloroformnarkose. Der 
postoperative Verlauf war normal und Patient konnte das Spital am 10. III. verlassen.

\section{Pathologisch-anatomische Untersuchung.}

Der Bulbus kam fürs erste in Müllersche Flüssigkeit, in weleher er ungefahr neun Monate verblieb. Die Nachhärtung wurde in steigendem Alkohol bewirkt. Nachdem aussen und innen je eine Kappe abgeschnitten worden war, wurde das Präparat in Celloidin eingebettet und nachber in vertikale Serienschnitte zerlegt. Zur Färbung wurden die gebräuchlichsten Tinktionsmittel verwendet, vornehmlich die Färbungen mit HämatoxylinEosin und Hämatoxylin-van Gieson. Vielfach habe ich die Sehnitte mikrochemisch auf Eisen untersucht, wozl ich die Perlssche Reaktion benutzte. Durch Nachfärbung der Schnitte mit Karmin erhielt ich gewöhnlich sebr anschanliche Bilder. Einige Schnitte unterzog jeh der spezifischen Färbemethode für Fibrin von Weigert, wie diese, so auch die einzeln angestelten Untersuchungen auf Bakterien mit Lofflerschem Methylenblan und nach Gram ergaben stets ein negatives Resultat.

Der Bubus ist von normaler Form und Woblbung. Der vertikale Durdmesser beträgt an Sclnitten, die der Mitte des Bulbus entsprechen, $24 \mathrm{~mm}$, der anteroposteriore $25 \mathrm{~mm}$.

Histologischer Befund. Die Cornea zeigt in ihrer änsseren Hälfte, nicht weit vom Zentrum, eine etwas schräg von oben nach unten die ganze Dicke durchsetzende geradlinige Narbe. Diese entspricht einer perforierenden Wunde, welche offenbar per primam und ohne Iriseinklemmung geheilt war. Die Narbe lässt sich bloss durch 15-20 Schnitte (à 20-25 $\mu$ ) verfolgen und warde intra vitam vermisst. Das Hornhautepithel ist fast überall erhalten, nur in einzelnen Präparaten fehlt es an einigen Stellen, vermutlich infolge der Konserviermng. Stellenweise erscheint das Epithel ödematös, hin und wieder begegnet man zwischen den Zellen einzelnen polynukleären Leukocyten. Die Membrana Bowmani ist leicht gequollen, an Stelle der Narbe fehlt sie ganz, an der Peripherie der Hornhant ist sie stellenweise verdünnt und faserig entartet. Hier liegt unter der Membran eine dünne Schicht älteren Granulationsgewebes, dieses arrodiert an einigen Stellen von hinten her die faserig gewordene Membran, durchsetzt sie und kommt zwischen letzterer und dem Epithel zu liegen. Auch vom Rande her, ohne die Bow mansche Membran za durchbrechen, schiebt sich auf eine kurze Strecke mitunter ein solches aus Rund- und Spindelzellen bestehendes und Blutkapillaren enthaltendes Gewebe in dümnster Schicht zwischen dem Epithel und der Membran hinein. Letzteres erseheint an genannten Stellen verdiekt. Das Granulationsgewebe in der Hornhaut steht in engem Zusammenhange mit einem stärker ausgebildeten und unten noch näher zu erörternden Gewebe in der Episklera. Die Grundsubstanz der Hornhaut zeigt ein lockeres Gefüge, die Saftucken sind erweitert und die Lamellen etwas anseinandergedrängt. Der Kermgehalt der Substantia propria ist bis auf die erwälnten der Membrana Bowmani anliegenden Schichten nicht vermeht.

Die Episklera ist mehr oder minder aufgelockert und verbreitert, am stärksten verdickt erscleint sie in den an den Limbus angrenzenden Teilen. Die Gefasse sind dilatiert und mit Blut gefullt. In ihrer Umgebung 
sieht man Anhäufungen von einkernigen Rundzellen, auch sonst begegnet man in der Episklera zelligen Elementen in mässiger Zahl, ausser Rundzellen findet man hier diffus zerstrent anch andere Zellen des Granulationsgewebes vor, freilich in der Minderzahl. Polynukleäre Leukocyten sind spärlich vertreten. Während in der Nähe des Limbus die Entzündungserscheinungen am stärksten ausgesprochen sind (Taf. XV, Fig. 1i) und diese auf die angrenzenden oberfächlichen Schichten der Hornhaut sich verbreiten, nehmen sie nach hinten recht schnell ab, doch lassen sich zellige Elemente meist in reihenförmiger Anordnung bis in die Gegend der Pars plana des Giliarkörpers verfolgen, auch hier sieht man sie vornehmlich um Gefässe angeordnet.

Die Sklera weist keine wesentlichen Veränderungen auf. Im vorderen Abschnitt ist ihr Kerngehalt etwas vermehrt, die hiex befindlichen pertorierenden Gefässe werden während ihres ganzen Verlaufes von Granulationszellen begleitet, doch ist diese perivaskuläre Lymphangitis (Axenfeld) nicht stark entwickelt. An den hinteren Ciliargefässen, so auch den Ciliarnerven habe ich zellige Einscheidungen nicht finden können.

Die Iris ist an ihrer Peripherie mit der Hornhantrückfläche verwachsen, nur unten liegt auf einer Strecke die Iris der Cornea nicht an und der Kammerwinkel ist hier offen. Die Pupille ist durch eine bindegewebige Membran vollkommen verschlossen, die Iris mit ihrem Pupillarrande an diese angewachsen. Die Iris hat im allgemeinen ein atrophisches Aussehen, sie ist dünner als gewöhnlich, nur am pupillaren und stellenweise auch am unteren ciliaren Ende erscheint sie ungleichmässig verdickt. Das Gewebe hat überall seine lockere Beschaffenheit eingebüsst. An Stelle des zierlichen Netzwerkes anastomosierender Zellen finden wir ein mehr straffes Bindegewebe. Die Zahl der fixen zelligen Elemente der Iris wie in der retikalären Schicht, so in der Gefässschicht ist bedeutend vermindert. Erstere ist an vielen Stellen ganz geschwunden, so dass das bindegewebige Stroma hier direkt an die vordere Kammer grenzt. Die übrig gebliebenen Zellen wie die pigmentierten, so die pigmentlosen sind meist atrophisch. Einige entbehren der Fortsätze und haben rundliche Form angenommen, mitunter sich zu unförmlichen Pigmentklumpen verwandelt. Die meisten Zellen haben jedoch ihre Fortsätze beibehalten, nur haben letztere ihre Länge eingebüsst und sind schmäler geworden. Die Kerne färben sieh oft weniger intensiv. In einzelnen Zellen sind letztere ganz geschwunden und der übrig gebliebene Zelleib wird durch Hämatoxylin-Eosin bald schwach rosa, bald fahlviolett tingiert. Viele der atrophischen Zellen verhalten sich ganz eigenartig zur genannten Tinktion, indem ihre Kerne rosa werden oder bei HämatoxylinOrangefärbung gelb, umgeben sind die Kerne zuweilen von einem schmalen violetten (Hämatoxylin) Protoplasmasaum. Bei Ölimmersion erkennt man, dass die violette Färbung hier an Körnchen gebunden ist, der Kern selbst erseheint diffus gefärbt. Diese Zellen haben meist ovale Form und entbehren der Fortsätze, doch wo solche noch vorhanden sind, erscheinen letztere sehr stark verdünnt und verkürzt und bleiben ungefärbt. Die Gefässe weisen fast alle verdickte, teils faserige, teils homogene Wandungen auf, ihr Lumen ist gewöbnlich verengt, oft ganz verschlossen. Da, wo ein solches zu sehen ist, erscheint das Endothel bald sklerosiert, bald suceulent, zuweilen des- 
quamiert, oft fehlt es ganz. Nicht selten sind die Gefässe aus dem Stroma ganz gesehwunden und ihr ehemaliger Sitz verrät sich mitunter noch durch den ihren früheren Wandungen entsprechenden typischen Faserverlauf oder dureh die cirkuläre Anordnung einzelner Endothelien und Stromazellen. Am stärksten anheimgefallen der Atrophie erscheint die obere Hälfte der Regenbogenhaut und der mit der Cornea verlötete periphere Teil der Membran.

Neben der soeben geschilderten Atrophie finden wir zugleich fast im ganzen Irisgewebe Anzeichen einer an versehiedenen Stellen verschieden stark ausgesprochenen chronischen proliferativen Entzundung. Am intensivsten tritt die Entzündung am pupillaren Teil der Iris hervor und am stärksten befallen erseheinen hier die hinteren Gewebssehichten (Taf. XV, Fig. 1). Auf Kosten dieser kommt auch die Irisverdiekung hier zu stande. Die Entzündung tritt unter dem Bilde einzelner rundlicher, hinter dem Sphinkter $(s p h)$ gelegenen Herde auf (Taf. XV, Fig. 1h). Diese werden von einer Menge kleiner einkerniger, dicht aneinandergedrängier Zellen gebildet. Letztere besitzen einen intensiv sich fürbenden, fast homogenen rundlichen Kern, von einem Protoplasma ist gewöhnlich nichts zu sehen, nur die an der Peripherie der Herde gelegenen Zellen lassen einen geringen Protoplasmahof erkennen (lymphocytoide Granulationszellen, Taf. XV, Fig. 2h). Die gewöhnlich im Querschnitt anzutreffenden Kapillaren sind mit Blut strotzend gefüllt und treten in der Zellenmasse als lichtere Ringe hervor. Die grösseren Herde haben den Sphinkter, den Bindegewebssepten folgend, durehwuchert und einige erstrecken sich sogar bis zur Irisoberfläche, nach hinten hat an einer Stelle die Infiltration auch die retinale Schicht der Iris zerstört und dringt in die hier gelegene retroiritische Schwarte hinein (Taf.XV, Fig. $1 g h$ ). In der Umgebung der Herde beobachtet man an vielen Stellen neben dem atrophischen Irisstroma neugebildetes derbes tibröses Bindegewebe, in welchem man ausser einzelnen spindligen, stärker tingierbaren Kernen anch eine ansehnliche Zahl grosser blasser (Endothelien) vorfindet. Die Gefässe sind hier meist obliteriert oder total geschwunden. Der Sphinkter, wo er von den Zellen nieht verdeckt wird, erseheint atrophisch. Ein paar Rundzellenherde finden sich auch in der Nähe des unteren Kammerwinkels vor, hier durchsetzen sie die ganze Irisdicke, sie erseheinen lang gestreckt und nicht so streng begrenzt wie am Pupillarrande. Einmal habe ich noch eine anselnnliche Zahl Rundzellen an der Vorderfäche der Iris, ein Gefäss um-

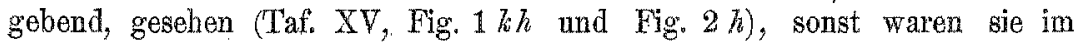
Stroma nur vereinzelt und selten anzutreffen.

Ansser diesen zu Herden gruppierten Rundzellen begegnen wir in der Iris noch einer andern Art von neugebildeten Zellen (Taf. XV, Fig. 2 u. 3). Diese haben bald runde, bald ovale, seltener polygonale Form und besitzen einen, seltener zwei excentrisch gelegene Kerne. Das Plasma erseheint meisí feinkörnig und färbt sich mit Eosin oft stark rot. Der Kern ist rundlich, grösser als bei den oben beschriebenen Rundzellen und nimmt eine weniger intensive Tinktion an. In grosser Menge trifft tman diese Zellen an der vorderen Iristläche an, wo sie unregelmässig angeordnet fast die einzige Zellart repräsentieren. Mit Vorliebe begleiten diese Zellen auch die Gefässe und an einigen Stellen findet man sie durch die Wandnngen der Kapillaren durchgewuchert im Lumen liegen (Taf. XV, Fig. $2 \approx w$ ). Im îbrigen Irisstroma 
ist diese Zellart nicht stark vertreten und liegen die Zellen gewöhnlich za mehreren beisammen. Einige der Zellen lassen einen protoplasmatischen Fortsatz erkennen, der verschieden lang sein kann, wodurch eine gewisse Ahnlichkeit mit den verzweigten Stromazellen der Iris $\mathrm{zu}$ stande kommt. Diese Ähnlichkeit wird noch grösser, indem diese Zellen Pigment aufweisen. Dieses unterscheidet sich doch von dem Bindegewebspigment recht deutlich durch seine grobkörnige Beschaffenheit und unbestimmte Form (Taf. XV, Fig. 2 u. 3 p). Irgendwelche bestimmte Beziehungen dieser Körner zu den Gefässen lassen sich nicht nachweisen, Blutungen fehlen überall. Nur sehr selten findet man vereinzelte frei im Gewebe liegende rote Blutkörperchen. Polynukleäre Leukoeyten sind ausserhalb der Gefässe nirgends nachzuweisen. Als ein nicht seltener Befund in der Iris muss noch das Vorkommen von hyalinen Kugeln verzeichnet werden. Diese sind fast in jedem Schnitt vertreten, sie farben sich recht intensiv mit den sauren Tinktionsmitteln, sind von verschiedener Grösse und liegen häufig zu mehreren beisammen. Die grösseren haben meist extracelluläre Lage, die kleineren liegen gewöhnlich in den oben beschriebenen plasmatischen Granulationszellen.

Die Pars iridis retinae zeigt wesentliche Veränderungen nur im pupillaren Tell. Hier ist das Pigmentblatt, wie schon oben erwähnt wurde, stellenweise durch die entzündliche Infiltration zerstört, an andern Stellen erweist es sich als verdickt und treibt sogar Fortsätze in die Tiefe (Taf. XV, Fig. 1 w). Sonst erscheint das Pigmentepithel nicht nennenswert verändert, nur in den peripheren Teilen der Iris ist das Pigment rarefiziert und die Kerne werden oft sichtbar. Die Limitans iridis ist stellenweise verdickt und tritt deatlich hervor.

Die vordere Irisfläche ist nirgends scharf begrenzt (Taf. XV, Fig. 2 u. 3), an einigen Stellen ist die Zahl der plasmatischen Zellen recht gross und letztere bilden kleine Hügel, an andern Stellen werden zellige Elemente an der Oberfläche, wie oben schon anseinandergesetzt wurde, überhaupt vermisst. Da, wo Zellen vorhanden sind, sieht man sie oft aus dem Gewebe in die Vorderkammer austreten (Taf. XV, Fig. 2), so dass stellenweise die vordere Irisfläche das Ansehen einer granulierenden Wunde (Knies) gewinnt. An vielen Stellen erhält man den Eindruck, als ob die Iris infolge des destruktiven Prozesses successive einschmölze, wobei ihre Elemente in die vordere Kammer übergehen. Man sieht mitunter Querschnitte von Gefässen, die einst eine tiefere Lage gehabt haben müssen, jetzt der vorderen Fläche der verdünnten Iris aufliegen. Nachdem die Zellen ihren Mutterboden verlassen haben, begeben sie sich bald einzeln, bald gruppenweise zur hinteren Hornhautfläche. Hier angelangt bilden sie an deren unterem Teile einen mehr oder weniger kontinuierlichen Belag (Taf. XV, Fig. 2), während im Zentrum sie sich zu abgegrenzten grösseren und kleineren, bald rundlichen, bald halbkreisförmigen Gebilden, den klinisch sichtbaren Präcipitaten, vereinigen. Diese Beschläge liegen inmitten einer geronnenen Eiweissmasse, welche in den meisten Präparaten als dünne Schicht die Hornhautrückfläche bedeckt. Die Masse hat ein fein granuliertes Aussehen und färbt sich mit Eosin rosarot. Sonst ist die vordere Kammer frei von Massen und jeglichen andern Bestandteilen bis auf die im Überwandern begriffenen zelligen Elemente (Taf. XV, Fig. $2 w e$ ). Fibrin ist nir-

จ. Graefe's Archiv für Ophthalmologie. LXXVIII, 2. 
gends nachzuweisen. In der Überzahl werden an der linteren Hornhautwand die plasmatischen Granulationszellen angetroffen, sie bilden hauptsächlich auch die circumseripten Präcipitate. In den kleineren und jüngeren sind die Zellen noeh wohl erhalten und lassen sich voneinander ziemlich scharf abgrenzen, in den grösseren und älteren Beschlägen liegen die Zellen gewöhnlich dicht aneinander gedrängt, ihre Grenzen erscheinen verwiseht und viele von ihnen sind im Zerfall begriffen. Sehr viele dieser Zellen enthalten wie die Iris dunkelbraunes grobkörniges Pigment (Taf. XV, Fig. $2 p i$ ), mitunter ist letzteres so stark vertreten, dass von einem Kerne und Zelleibe nichts zu sehen ist und die Präcipitate hauptsäehlich aus angehäuften dunkelbraunen Körnchen zusammengesetzt erscheinen. Auch die diffuse Zellenauflagerung wird vomehmlich durch die eben genannte Zellenart gebildet (Taf. XV, Fig. 2). Rundzellen sind überall in der Minderzahl vertreten. Noch seltener werden hier die fixen zelligen Elemente der Iris angetroffen, diese lassen meist deutlich ihre Fortsätze erkennen und enthalten mitunter auch Stromapigment. Rote Blutkörperchen und polynukleäre Leukocyten sind bloss vereinzelt und nur in ein paar Präparaten anzntreffen. Etwas häufiger kommen inmitten der Zellenauflagerungen hyaline Kugeln zur Beobaehtung; diese liegen meist vereinzelt und extracellulär. Im allgemeinen scheinen die Lebensbedingungen für die in die vordere Kammer geratenen zelligen Elemente nicht besonders günstig zu sein. Auch dort, wo letztere lockerer liegen, zeigen sehr viele ein anormales Aussehen, sie erscheinen gequollen, ihr Protoplasma getrübt und am Rande wie zerfetzt, die Kerne färben sich weniger intensiv. Angefangen von diesen regressiven Formen lassen sich alle Stadien bis zum vollständigen Zerfall verfolgen. Die fixen Stromazellen scheinen die Iris überhaupt erst im degenerierten Zustande zu verlassen, dasselbe gilt anch in vielen Fällen für die plasmatischen Granulationszellen.

Die Desce m ets ch e M e m b ran zeigt keine nennenswertenVeränderungen, nur an Stelle der Narbe erfährt sie eine Unterbrechung. Das sie überkleidende Findothel erscheint streckenweise abgehoben, vermutlieh infolge der Konservierung, an vielen Stellen erweist es sich als recht erheblich alteriert. An gewöhnlichen Meridionalschnitten bemerkt man, dass viele Kerne eine schwächere, oft gar keine Tinktion annehmen, besonders fallt dieses an Stellen auf, wo dem Endothel grössere pigmenthaltige Präcipitate anliegen. Am besten Einsicht in die Beschaffenheit des Endothels gewinnt man, wo dieses infolge schräger Lage der Schnitte von der Fläche sichtbar wird. Oft ist hier von einzelnen Zellindividuen nichts mehr zu sehen, die Grenzen zwischen ihnen sind verwischt und das ineinandergeflossene Protoplasma hat sich za einer feingekörnten, mit Eosin rosa gefärbten Masse verwandelt, in welcher man in gewissen Abständen nur noch die Kerne vorfindet. Diese sind gleichfalls verändert, was aus ihrem versehiedentliehen Verhalten zu Kernfarben, wie oben bereits mitgeteilt wurde, folgt. Anell dort, wo die Zellen sich noch als Einzelindividuen präsentieren, zeigen sie oftmals $\mathrm{Va}$ kuolenbildung, Quellung nnd ungenügende Fầrbung des Kernes. Stellenweise kommt in den Endothelzellen auch braunes feinkörniges Pigment zur Beobachtung, einigemal liessen sich in ihnen gruppenweise angeordnete hyaline Kugeln nachweisen. Nicht selten haben sich dio Endothelien abgelöst und liegen frei in der vorderen Kammer. Solche Zellen erscheinen gewöhnlieh 
vergrössert und zeigen nicht minder ausgesprochene pathologische Beschaffenheit als die am Mutterboden haftenden (Taf. XV, Fig. 2 en).

Neben den genannten regressiven Erscheinungen begegnet man im unteren Teil der Hornhaut auch einigen wenigen Stellen, die auf Vermebrung and Wucherung der Endothelien hinzudeuten scheinen. Als Resultat proliferativer Tätigkeit des Descemetsehen Endothels ist auch eine an dem untersten Teil der Corneahinterfläche anzutreffende bindegewebige Auflagerung anzusehen (Taf. XV, Fig. 3 b). Diese zeigt zum gxössten Teil lamellären Bau und ist kernhaltig. Die Kerne erinnern auf den ersten Blick an vergrösserte Hornhautkörperchen, doch lässt sich in den meisten Präparaten ihre Abstammung vom Endothel und das Hervorgehen des Gewebes aus letzterem nachweisen. Hin und wieder trifft man in der Auflagerung grobkörniges Pigment an, dieses scheint wie inter- so auch intralamellär zu liegen. In den zentralen Teilen der Auflagerung konfluieren häufig die Lamellen miteinander, stellenweise verschmelzen sie vollständig zu einer homogenen Masse, wobei die Kerne zugrunde gehen. Wie an andern Stellen der Hornhautwand, so finden wir auch an der Oberfläche der beschriebenen Anflagerung Beschläge vor:

In der unteren Kammerbucht sammeln sieh die Zellen zu grösseren Mengen an und durchsetzen von hier aus die Maschen des Ligamentum pectinatum (Taf. XV, Fig. $3 \quad l p$ u. ez). Die Zellen umgeben mantelförmig den Sehlemmschen Kanal und die vorderen Ciliargefässe und hängen mit der eingangs geschilderten perivaskulären Lymphangitis in der Sklera und Episklera zusammen. Ein anderer Zug von Zellen begibt sich zum Ciliarkörper.

Der Ciliarkörper, so auch die Aderhaut sind leicht abgehoben (Taf. XV, Fig. 1), wahrscheinlich infolge der Härtung. Die Lamellen der Suprachorioidea erscheinen ausgedehnt, ein Erguss fehlt. Die Muskulatur des Ciliarkörpers ist atrophisch, das bindegewebige Stroma, wie zwischen den Muskelfasern, so auch an den Fortsätzen und in der Pars plana erscheint verdiekt, vielfach sklerotisch and hyalinisiert. Letztere haben meist dickere und kürzere Form angenommen, wodurch der Ciliarkörper auch ein plumperes Aussehen gewinnt (Taf. XV, Fig. 1). Der Kerngehalt im Stroma ist etwas vermehrt, nur im vordersten Teil des Ciliarkörpers an der Grenze zwischen der inneren Oberfläche des Muskels und dem Stroma der Ciliarfortsätze findet man unten eine mehr oder weniger begrenzte Ansammlung junger Granulationszellen, die, wie schon erwähnt wurde, in die Infiltration der Iriswurzel übergeht. Die Gefässe des Ciliarkörpers zeigen meist verdickte Wandungen, viele sind bluthaltig, die der Pars plana sind alle mit Blut strotzend gefüllt. Grobkörniges braunes Pigment ist nur vorne im Stroma des Faltenteils und in geringer Menge anzutreffen. Die Zahl der Bindegewebspigmentzellen ist dagegen vermehrt und sie erseheinen stark verästelt. Höchst selten begegnet man im Stroma hyalinen Kugeln. Das Pigmentepithel des Ciliarkörpers bietet keine nennenswerten Veränderungen, stellenweise erscheint es rarefiziert. Als Besonderheit der inneren normaliter unpigmentierten Zellage fällt hier eine ausgedehnte Pigmentierung der Epithelien auf. Die Limitans c. cil. tritt an einigen Stellen hervor and erscheint verdickt.

Genauere Besprechung erfordert der flache Teil des Ciliarkörpers im 
unteren Bulbusabschnitt. In allen Präparaten lenkt hier schon makroskopisch auf sich die Aufmerksamkeit die Anwesenheit einer eigenartigen Bildung (Taf. XV, Fig. $1 \mathrm{f}$ ). Diese hat im Schnitt nahezn Dreiecksform, beginnt in den meisten Präparaten an der Ora serrata und erstreckt sich ron hier aus ungefähr $1 / \int_{2} \mathrm{~mm}$ weit nach rorne, nach innen nicht weiter als $1 / 2 \mathrm{~mm}$. In Schnitten, die der Pupillengegend entsprechen und nach innen noch darüber hinaus fiadet sich in die genannte Formation ein eigenartiges Gebilde (Taf. XV, Fig. 18 ) eingelagert, makroskopiseh schon als dunkler Punkt kenntlich (verrostetes Eisenfragment). Letzteres setzt sich aus derben, dicht nebeneinander liegenden, leicht spiralig gewundenen Strängen zusammen. Diese ersheinen bald grunlich, bald grau, bald rostfarben. Ausserdem findet sich in der Umgebung des genannten Körpers noch eine Anzahl kleinerer Partikel vor, diese besitzen keine bestimmte Form, erscheinen rostfarben and haben meist ein glänzendes Aussehen. Die beschriebenen Gebilde liegen gewöhnlich in Bindegewebe eingebettet. Letzteres ist verhältnismässig kernreich, besitat bluthaltige Kapillaren und erscheint an vielen Stellen derbfaserig, nicht selten hyalinisiert. Diese Bindegewebsmasse macht anch den grössten Teil der Formation aus. Letztere liegt breitbasisch dem Pigmentepithel anf. An einigen Stellen erscheint das Epithel, so auch die Glasmembran unterbrochen und hier tritt der Zusammenhang der bindegewebigen Auflagerung mit der Uvea markant hervor, indem durch die Liicken ein ausgesprochener Faseraustausch zwischen beiden Teilen zu stande kommt. Das Pigmentepithel geht dabei Wucherungen ein. Es überzieht vom Rande her als Zellhäutchen die Bindegewebsmasse und grenzt somit lotztere vom inneren Angenraum ab. Diese Membran findet sich in allen Schnitten vor, besteht aus einer einschichtigen Lage wohlausgebildeter kubischer und voneinander scharf abgegrenzter Zellindividuen. Diese erinnern an Endothelien, enthalten meist Pigment und liegen überall einer strukturlosen Limitans auf. Ein Übergang dieser Zellen in das Pigmentepithel ist fast an sämthehen Präparaten einwandstrel̆ nachzuweisen. In einigen Sehnitten lässt sich die Membran auch eine Strecke linter der Ora sermata auf der inneren Obertüche der Netzhaut verfolgen, nach vorne geht sie auf die äussere Oberfäche des abgehobenen Glaskörper über, wo sie aber bald versehwindet. Ganz vorne jedoch fehlt die beschriebene Zellmembran auf einer kurzen Strecke und bier grenat das Bindegewebe direkt.an die verdickten Fibrillen des abgelösten Glaskörpen.s. Fernex führt das wuchernde Pigmentepithel zur Bildung schmaler, meist spindelförmiger Hohlräume und Kanale im Inneren der Bindegewebsmasse. Diese Räume werden gleichfalls von einer einschichtigen Lage teils pigmenffreier, teils pigmentierter Zellen ausgekleidet. Seltener kommt es zur Bildung solider Stränge. Auch die Zellen der inneren Lage der Pars ciliaris ret. sind gewuchert. Am auffallendsten tritt die Proliferation der Epithelien rings um die Auflagerung zutage. Die gewueherten Zellen erscheinen dabei erheblich verändert, ihre Grenzen sind oft nicht mehr sichtbar, sie haben meist längliche Form angenommen und zeigen Vakuolen, oft kommt es zur Höhlenkildnng in den Zellkomplexen. Viele Zellen haben Pigment aufgenommen. Nirgends jedoch liegt diese Art von Wucherung dem Bindegewebe direkt an, überall wird sie von letzterem durch eine Schicht proliferierten Pigmentepithels deutlich abgegrenzt. Durchmustert man in temporaler Richtung die 
Iridochorioiditis serosa nach langiuhr. Verweilen eines Eisensplitters usw. 279

Schnitte, so kann das allmähliche Schwinden der Bindegewebsmasse aufs beste verfolgt werden. Gleichzeitig gelangt man zur Einsicht, dass die oben bereits geschilderten Einlagerungen nicht uiberall von einer bindegewebigen Kapsel umgeben sind, sondern zuweilen direkt an die epitheliale $W$ ucherung, seltener an den verdickten Glaskörper grenzen. Nasalwärts kann die Bindegewebsmasse nicht ganz bis zum Ende verfolgt werden. Nach dem Aufhören der Partikel nimmt das Bindegewebe stark sklerotische Beschaffenheit an, und inmitten dieses tritt eine aus typischem Knochengewebe gebildete Platte zum Vorschein. Letztere konnte ungefähr durch 12-15 Schnitte verfolgt werden, hatte lappenförmige Gestalt und nahm den grössten Teil der Masse ein. Der Kerngehalt war in der Umgebung nicht wesentlieh vermehrt. Weiter folgte wieder sklerotisches Bindegewebe.

Der Glaskörper ist abgehoben. Oben erstreckt sich die Ablösung bis zur Ora serrata, unten bis zum vordersten Teil der beschriebenen Prominenz. Der als kleiner Rest im vorderen Bulbusabschnitt vorhandene Glaskörper erscheint bedeutend dichter als der normale und ist an vielen Stellen von grösseren ein-, seltener zwei- und mehrkernigen Zellen mit deutlich ausgesprochenem Protoplasmaleib durchsetzt. Viele enthalten Pigment, dieses erscheint bald in Form von braunen unregelmässigen Körnern, bald als schwarzbraune Pünktchen. Trotz der Degenerationserscheinungen, die viele dieser Zellen aufweisen, fällt es nicht schwer, sie von Pigmentepithelien abzuleiten. Ein geringer Teil der Zellen im Glaskörper stammt von der innersten Epithellage des Ciliarkörpers.

Die Linse ist geschrumpft. Beim Schneiden bröckelt sie. Die der Untersuchung zugänglichen Reste erscheinen gänzlich kataraktös und teils verkalkt. Die Kapselepithelien haben stellenweise einen bräunlichen Farbenton angenommen. Die vordere wie die hintere Kapsel zeigen starke Faltenbildung und sind im Pupillargebiet unterbrochen. Die Epithelien erscheinen stellenweise vorne zu einem Kapselstargewebe gewuchert. Der vorderen LinsenAäche liegt eine zu Bindegewebe organisierte Exsudatmasse auf. Diese beschränkt sich fast aussehliesslich auf die Pupillenregion und ist, wie oben erwähnt wurde, mit dem Irisrande total verwachsen. In dem der Linse anliegenden Teil stellt das Bindegewebe eine ältere narbenartige Schwarte mit spärlichen platten Zellen dar, näher zur Iris ist es zellenreich und enthält Kapillaren. Die Zellen bestehen meist aus plasmatisehen Granulationszellen, weniger aus einkernigen Rundzellen und Endothelien. Ferner begegnet man hier Bindegewebspigmentzellen, diese baben schön ausgebildete Fortsätze und sind von der Iris eingewandert. Auch ungeformte braune Körner kommen hier zn Beobachtung. Die vordere Fläche der Exsudatmembran wird von einer einschichtigen Lage langgestreckter, teils pigmenthaltiger, von der Lrisoberfläche stammenden Zellen überzogen. Sonst sind im Auge nirgends an der Oberfläche Anzeichen eines fibrinösen Exsudats oder daraus hervorgegangener Schwarten zu verzeichnen. Die Irishinterfläche, so auch zum grössten Teil die Pars cil, ret. sind gleich der Hornhautrückfläche von einer dünnen Schicht einer feingrannlierten Eiweissmasse bedeckt.

Die Aderhaut ist verdiekt, in den linteren Partien mehr als in den vorderen. Ihre innere Oberfläche erscheint stellenweise unter dem Einflusse der Härtungsflüssigkeit unregelmässig eingezogen und sieht wie gerunzelt 
aus. Die Aderhaut ist durehweg verändert und die Veränderungen sind denen des vorderen Abschnittes der. Uvea ähnlich. Man begegnet in der Aderhaut einer mässigen Anzahl einzeln liegender, mehr oder weniger streng: begrenzter Herde. Sie kommen in der ganzen Chorioidea vor, doch scheint ihr Lieblingssitz die Gegend des Äquators (Taf. XV, Fig. 1 a ha ) und des hinteren Poles zu sein. Ihrer Form und Zusammensetzung nach unterscheiden sich die Herde nicht von denen der Iris. Die meisten sind rundlich und die sie bildenden Rundzellen liegen dicht aneinander, in den langgestreckten Herden bemerkt man oft eine reihenweise Anordnung der Kerne. Die meisten der genannten Herde erstreeken sich durch die ganze Dieke der Chorioidea bis zur Glasmembran, doch sind einzelne bloss auf die Sehicht der grossen und mittleren Gefässe beschränkt; in diesen Fallen liegen die Zellen lockerer und lassen einen geringen Protoplasmasaum erkennen. Ein ausschliessliches Vorkommen der Herde in der Ohoriocapillaris bei Freibleiben der äusseren Schichten konnte niemals beobachtet werden. Ein Übergreifen der Infiltration auf die Retina kam gleichfalls nie zu stande. Die Herde scheinen in gewissen Bezielungen zu den Gefässen, insbesondere den Venen zu stehen. Nur die allerkleinsten liegen etwas entfernt von den Venen, die grösseren liegen alle den letzteren an oder umgeben sie auf dem Querschnitt von zwei gegeniberliegenden Stellen. Die langgestreckten Herde begleiten die Gefässe auf längere Strecken. An einer Stelle durchsetzen die Rundzellen sogar die Gefässwand und erfüllen anf diese Weise zum Teil das Lumen der Vene, letztere verhält sich dabei ganz passiv. Plasmatische Granulationszellen finden sich im Gegensatze zur Iris in der Aderhaut in geringer Anzahl vor. Sie liegen diffus zerstreut, häufiger zu mehreren beisammen.

Die Zeichen der frischen chronischen Entzündung sind in der Chorioidea im allgemeinen doch mässig vertreten. In den Vordergrund tritt aber die Neubildung von Bindegewebe. Letzteres erscheint besonders stark ausgesprochen in den hinteren Absehnitten der Chorioidea, nach vorne nimmt die Bindegewebsproliferation allmählich ab. Im Anfange zeigt das neugebildete intervaskuläre Gewebe eine leichte, zur Oberfläche beinahe parallele Streifung, die oben beschriebenen Granulationszellen fehlen fast ganz und an ihrer Stelle sieht man grössere, längliche blasse Kerne. Später nimmt die Zahl der letzteren $a b$ und das Gewebe nimmt stellenweise fibrilläre $\mathrm{Be}$ schaffenheit an, an andern Stellen schreitet die bindegewebige Umwandlung des Aderhautstroma noch weiter und es kommt zur Bildung eines derben, sklerotisehen, selbst hyalinisierten Narbengewebes (Taf. XVI, Fig. 4). In solchen Fallen ist die Choriocapillaris meist untergegangen und die Bindegewebsmasse erstreekt sich bis zur Vitrea $(D)$. Letztere seheint dem Weitersehreiten des Prozesses Einhalt zu gebieten, stets habe ich sie unversehrt gefunden. An einer Stelle in der Nähe des hinteren Poles kam es sogar zur typischen Knochenbildung $(K n)$ inmitten so einer Schwiele, die Glaslamelle zog ungestört durch die Knochenplatte hinweg. Die in der Nähe der Rundzellenherde liegenden Gefässe exscheinen erweitert und bluthaltig. Die meisten Gefässe zeigen verdickte Wandungen und ein verengtes Lumen. Mitunter ist letzteres ganz obliteriert und die Gefässe erscheinen in solide bindegewebige Stränge verwandelt $(b g)$. Die Verdickung kommt meist auf 
Kosten der Adventitia zu stande und diese geht oft unmerklich in das umgebende Bindegewebe über (Taf. XVI, Fig. 4). Wucherungen der Intima werden seltener beobachtet. Die Zahl der Stromapigmentzellen hat bedeutend zugenommen. Sie sind in der ganzen Aderhaut, wo sich neugebildetes Bindegewebe vorfindet, in grosser Anzahl anzutreffen, recht oft sogar in der ehemaligen Kapillarschicht, wo normaliter Pigmentzellen fehlen. Häufig trifft man sie am Rande der Rundzellenhanfen an, nicht selten beobachtet man sie sogar in den alterierten Wandungen der Gefässe und in den nach $O b$ literation der letzteren entstandenen Strängen. Extracellulärliegendes Pigment oder braune unförmliche Körner, wie in andern Teilen des Auges, sind in der Aderhant nicht nachzuweisen.

Die Netzhaut ist von nngleichmässiger Dicke, nur in der Umgebung des Sehnerven erscheint sie stellenweise verbreitert, sonst ist sie schmäler als normal. Sie liegt der Aderhant an und ist mit letzterer streckenweise verlötet, dazwischen kommt es häufig zu flachbogenförmigen mikroskopischen Abhebungen (Taf. XVI, Fig. 4). Die Netzhaut zeigt sich uberall erheblich verändert. Das Pigmentepithel haftet meist der Chorioidea an, an einigen Stellen ist es desquamiert, an andern fehlt es vollständig. Die Epithelzellen erscheinen fast durchweg degeneriert, man findet hier die versehiedensten Bilder vertreten, angefangen von geringer Vakuolisation, leichter Rarefizierung des Pigments und kaum nennenswerter Formveränderung der Zelle bis zum vollständigen Zerfall der letzteren und Freiwerden ihres Pigments, ähnlich wie es bei der Retinitis pigmentosa und nach künstlicher Unterbrechung der Aderhautcirkulation zu wiederholten Malen von den Autoren [Wagenmann (42), Krüzckmann (23) u. A.] beobachtet und beschrieben worden ist. Am hochgradigsten alteriert erscheinen die in die erwähnten subretinalen Räumchen $(s r)$ desquamierten Elemente $(p d)$. Erstere erscheinen gewöhnlich vollgepfropft von Zerfallsprodukten der Epithelien, welchen sich noch solche der Stäbchen und Zapfen hinzugesellen. Vielfach erscheint das Pigmentepithel wieder gewuchert, die Zellen liegen in mehreren Schichten übereinander und bilden halbkugelartige Hervorragungen, aus diesen sieht man nicht selten homogene Gebilde, die sogenannten Drusen der Glaslamelle entstehen. Letztere erstrecken sich bisweilen recht weit in die Netzhaut $(d)$, konfluieren mitunter mit den noch später näher zu erörternden obsoleten degenerierten Retinalgefässen $(g)$ und bilden homogene Flächen.

Stäbchen und Zapfen sind nirgends vorhanden, man sieht nur stellenweise ihre Triimmer unter der multipel abgelösten Retina liegen. Von den übrigen Netzhautschichten finden wir nur noch in der Umgebung der Papille Andeutungen in Form von zusammenliegenden Körnern $(k)$. Am hinteren Pol treten fleckenweise sehr deutlich die vertikal verlaufenden $\mathrm{Müller-}$ schen Siützfasern hervor, diese sind beträchtlich verdickt und erscheinen teils homogen, teils faserig. An den übrigen Stellen erscheint die Retina in eine retikuläre Fasermasse umgewandelt. Der Kerngehalt ist an verschiedenen Stellen ein wechselnder und zeichnen sich die Kerne durch mannigfache Form, Grösse und Tinktion aus. Nur an Stelle der ehemaligen Nervenfaserschicht nimmt das Gliagewebe faserige Anordnung an und verlaufen die Fasern der Oberfäche parallel $(n)$. 
Die Gefässe sinđ stark verändert, ihre Wandungen faserig, meist glasig verdickt, oftmals völlig obliteriert und in homogene Schollen und Stränge umgewandelt $(g)$. Diese Gebilde erstreeken sich mitunter bis zur äusseren Netzhantoberfläche und verschmelzen, wie schon erwähnt, mit den aus den Wucherungen des Pigmentepithels entstandenen Drusen. Frwähnung bedarf noch das Vorkommen von nengebildetem Bindegewebe in der Retina. Das jüngere Gewebe liegt meist dicht unter der inneren Oberfläche der Netzhaut. An einigen Stellen sieht man dieses Gewebe die Gefässe einscheiden, besonders deutlich tritt aber der Zusammenhang mit dem adventitiellen Gewebe an den Zentralgetässen und ihren ersten Verzweigungen zutage. Mehr nach vorne macht sich die Relation des Gewebes zu den Gefässen weniger bemerkbar, die Bindegewebsmasse nimmt hier grössere Dimensionen an und substituiert an einigen Stellen völlig die ganze Retina. Während an den peripheren Teilen dieser Gewebsmasse die Kerne sowie die einzelnen Fasern noch hervortreten, sind diese Elemente in den zentralen Teilen als solche nicht mehr zu erkennen und das Gewebe hat hier ein mehr homogenes Aussehen erhalten. Durch die van Giesonsche Färbung wird dieses Gewebe rot, während die Fasern der Glia überall gelb werden. Auch die Färbung mit Pikro-Indigo-Karmin gibt ein sehr anschauliches Bild, indem das mesodermale Gewebe zum Untersehiede von dem ektodermaler Abkunft, welches gelblichgrün tingiert ersoheint, eine intensitr blaue Färbung annimmt.

Ferner enthäl die Netzhaut an vielen Stellen Pigment. Dieses hat entweder das Aussehen grösserer rostbrauner Körner, oder unterseheidet sich nicht von den Farbstoffkörnchen des Pigmentepithels. Letztere Pigmentart ist weniger stark vertreten. Wie diese, so anch jene nelmen hauptsächlich die aussere Netzhauthalfte ein und erscheinen dabei im Gewebe gleichartig angeordnet und verteilt. Von anssen nach innen nimmt der Reichtum an Pigment allmählich ab. Letzteres scheint an das gliöse Gewebe gebunden zu sein, frei in den Retinallacunen ist es mit Bestimmtheit nicht nachzuweisen. Stärker angehäuft findet man das Pigment nicht selten um die Gefässe und die Bindegewebsmassen. Auch die gewucherten Epithelien erscheinen stellenweise überfullt ron Pigment, frei im Gewebe sind Epithelzellen nieht anzutreffen, itberall stehen sie in direkter Kontinuität mit den präformierten Pigmentepithelien.

Neben den beschriebenen proliferativen Erscheinungen begegnen wir in der Netzhaut nicht weniger hänfig Veränderungen regressiver Natur. Diese äussern sich in Schrumpfung und Zerfall des gliösen Gewebes. Nur im hintersten Bulbusabschnitt ist die Retina verdickt, mehr nach vorne erscheint das gliöse Gewebe ziemlich stark geschrumpft und verschmälert. Die Zerfallserscheinungen beginnen schon in der Nähe des Sehnervenein trittes. Man sieht hier vielfach nebeneinander Lücken auftreten, in deren Innerem neben degenerierten Zellen und Faserteilen eine fein granulierte Masse sich porfindet, diese wird wohl als ein Zerfallsprodukt der genannten Netzhautelemente aufatufassen sein. Am Rande der Litcken erscheinen die Gliaelemente wesentlich alteriert, auf Kosten deren allmähliches Einschmelzen erstere sich vergrössern. Nither zur Ora serrata trifft man Stellen an, wo von der Netzhaut nichts mehr zu sehen ist und das veränderte Pigment- 
epithel von dem inneren Augenraum bloss durch eine Schicht feinkörnigen Detritus abgegrenzt wird.

Auf der inneren Netzhautoberfläche finden wir sehr oft eigenartige ku'glige $(k g)$ Gebilde. Diese sind von wechselnder Grösse, erscheinen scharf konturiert und meist von einem kaum wahrnehmbaren feinkörnigen Saum umgeben. Ihr Inneres ist gleichfalls von einer ähnlichen Masse ausgefuillt, oft jedoch erseheint es ganz leer. Selten kommt hier ein Kern zur Beobachtung. Diese Gebilde liegen dicht aneinandergedrängt in einreihiger Schicht. Hin und wieder ballen sie sich zu kleinen Hügeln zusammen. An Stellen, wo die Retina zugrunde gegangen ist und das Pigmentepithel frei liegt, sieht man die Gebilde inmitten der körnigen Masse sebr zahlreich vertreten und der allmähliche Übergang von den Pigmentepithelien zu den kugligen pigmentlosen Gebilden lässt sich ungezwungen verfolgen. Letztere werden $\mathrm{ab}$ und $\mathrm{zu}$ auch im abgelösten Glaskörper in der Nähe des gewucherten Pigmentepithels beobachtet, doch hier tritt ihre Relation zu Zellen nicht so evident hervor. Da, wo die kugligen Gebilde fehlen, ist die Netzhautoberfäche meist von einem geringen feinkörnigen Besatz, ähnlich dem an den Kugeln haftenden, bedeckt.

In der Nähe des Sehnerveneintrittes findet man die Innenfläche der Retina eine Strecke weit von einer einschichtigen Lage endothelartiger Zellen überkleidet $(e)$. Diese haben kubische Form, sind gewöhnlich voneinander streng abgegrenzt und besitzen noch verhältnismässig gut tingierbare Kerne. Da, wo die Zellmembran als solche aufhört, sieht man ibre Zellen gleichfalls successive in kuglige Gebilde sich umwandeln. Näher zum Optikus wird das Häutchen mehrschichtig, die Zellen verlieren ihr endotheliales Aussehen, sie werden platt und unregelmässig. Residuen eines ähnlichen Häntchens werden stellenweise auch mehr nach vorne auf der Innenfläche der bindegewebigen Massen bemerkt.

Der Sehnervenkopf ist glaukomatös excaviert. Auf der Oberfläche der Exeavation findet sich gleichfalls eine einschichtige Lage genannter kugliger Gebilde vor. Die Excavation ist teilweise durch Gliawucherung ausgefuilt. Die Nervenfasern sind im Optikus völlig geschwunden, auf Kosten ihrer erscheint überall die Glia gewuchert und das interstitielle Gewebe vermehrt. Die Gefässe zeigen Wandverdickung und sind von faserigem Gewebe eingehüllt. Unmittelber hinter der Lamina cribrosa erscheinen sie von einem dichten Rundzellenmantel umgeben, doch nimmt der Kerngehalt nach hinten bald beträchtlich $a b$. In den Sehnervenscheiden findet man an einigen Stellen leichte Kernvermehrung.

Mikrochemisehe Untersuehung. Die Berlinerblau-Reaktion ergab sehr befriedigende Resultate, doch war dazu eine genügend lange Einwirkung der Reagentien erforderlich. Wurde die Reaktion nach den allgemein üblichen Vorsehriften ausgeführt, so war das Resultat ein mangelhaftes. Sehr leistungsfähig erschien mir das Verfahren v. Hippels $\left.(17)^{1}\right)$. Am intensiv-

1) $10 \%$ ige Ferrocyankaliumlösung und chemisch reine Salzsäure in ungefähr gleichen Mengen zusammengegossen und mit destilliertem Wasser stark verdünnt. Die Schnitte verbleiben in dieser Lösung 12-24. Stunden. Nachher sorgfältiges Auswässern in Brunnenwasser. 
sten tritt die Reaktion an dem eingangs beschriebenen Frem dkörperbett auf. Die eingelagerten Gebilde nehmen alle fast momentan eine tiefblaue Färbung an. Das gewucherte Pigmentepithel wird an vielen Stellen intensiv blau, wobei nicht allein das Protoplasma, sondern anch das Pigment gefärbt wird. Das ubrige Pigmentepithel des Ciliarkörpors verhält sich verschieden zur Reaktion, indem es im flachen T'eil meist eine dunkelblaue Tinktion annimmt, im Faltenteil dagegen gewöhnlich von der Reaktion unbeeinflusst bleibt. Die innere normaliter unpigmentierte Epithellage erscheint überall intensiv himmelblau und die in sie eingelagerten Körnehen dunkelblau, ähnlieh tingiert werden auch die braunen unförmlichen Körnehen im Stroma der Fortsätze. Das Pigment in den Stromapigmentzellen behält überall die ihm zukommende braune Färbung. In der Iris werden die in den plasmatisehen Granulationszellen liegenden braunen Körner alle intensiv blau. Auch findet man im Protoplasma der Stromazellen häufig blaue Körnchen vor, seltener erscheint letzteres von diesen ganz vollgepfropft, der Kern dagegen bleibt frei und wird dureh Karmin lebhaft rot tingiert. Ähnliche Bilder werden zuweilen an den Granulationszellen beobachtet, doch meist sind sie überladen von eisenhaltigem Pigment und dieses lässt den Kern nicht hervortreten. Die meisten Stromazellen, so auch der retinale Teil der Iris bleiben von der Reaktion unbeeinflusst. Ferner begegnet man in der Sphinktergegend einer Anzahl ovaler, diffus hellblau gefärbter Kerne, diese sind mitunter von einem schmalen dunkelblauen feinkörnigen Protoplasmasaum umgeben. Seltener bemerkt man an diesen Zellen noch Residuen ungefärbter Fortsätze, oft ist von einem Protoplasma überhaupt nichts za sehen. Von diesen Zellen war oben schon die Rede und sie entsprechen denjenigen Elementen, deren Kerne mit Hämatoxylin nicht gefärbt wurden und eine Färbung mit sauren Tinktionsmitteln eingingen. Frei im Gewebe liegendes Eisen konnte nicht nachgewiesen werden. Das an die Präcipitate gebundene Pigment erweist sich fast überall eisenhaltig; nur selten begegnet man Bindegewebspigment in atrophischen Stromazellen, auch die in den Maschen des Lig. peet., in der bindegewebigen Pupillarmembran und in der Auflagerung an der Horahautrückfläche vereinzelten braunen Körner geben eine lebhafte Eisenreaktion. Die Kapselepithelien werden stellenweise diffus blau. Die in einigen Zellen des Glaskörpers liegenden braunen Körner nehmen auch eine intensive Blaufärbung an. Auffallend schön reagiert anf Eisen die Retina. Die gewucherte Glia erscheint diffus himmelblan gefärbt, während das mesodermale Gewebe - die verdickten Gefässwandungen und die eingelagerten Bindegewebsmassen - ungefärbt bleibt. Die in der Retina zerstrenten unförmlichen bräunlichen Körnchen werden dunkelblau, daneben sieht man aber auch in den Fasern, in den Zellen und um die Gefässe braunes Pigment. Das Pigmentepithel zeigt grösstenteils die ihm zukommende braune Färbung, an Stellen aber, wo es gewuehert ist, erseheinen die Zellen, so auch die in ihnen liegenden Körnchen oftmals intensiv blau gefärbt. Die in die subretinalen Räumchen desquamierten Epithelien nehmen alle diffuse Blaufärbung an, zuweilen anch die in den intraretinalen Lücken befindlichen Zelltrümmer. Seitens der Aderhaut fällt die Reaktion negàtiv aus. Die Sklerz and Cornea nehmen einen ganz leichten grünlichen Ton an. Das Hornhautepithel, das Descemetsche Endothel, so auch die binde- 
gewebige Anflagerung erscheinen etwas tiefer tingiert. Einen grünlichen Ton nimmt auch die der hinteren Hornhautfläche anliegende feinkörnige Masse an.

Zwecks genauerer Differenzierung des normalen Pigments vom pathologischen wurden einige Schnitte in eine konzentrierte Salzsäurelösung $(1: 4)$ gebracht. Erst nach dreimal 24 Stunden hatte sich das Eisen vollständig gelöst und eine jegliche Reaktion auf das Ferrocyankalium-Salzsäuregemisch blieb aus, das Pigmentepithel war etwas heller geworden, das Stromapigment der Urea blieb unverändert. Bei Behandlung der Schnitte mit schwächeren Lösungen $(1: 20)$ kam man schwerer zum Resultat, so konnte noch nach sechs Tagen Eisen in den Retinakörnchen nachgewiesen werden und die Reaktion trat an letzteren sogar früher ein als gewöhnlich.

Ferner habe ich noch ein paar Sehnitte mit Aq. chlori behandelt und erzielte hier, ähnlich wie Hertel, nach 5-6 Tagen Entfärbung des normalen Pigmentgewebes, während das eisenhaltige Pigment unverändert blieb und eine deutliche Eisenreaktion gab.

Fassen wir die pathologisch-anatomischen Veränderungen zusammen, so ergibt sich folgendes: Chronische proliferative Entzïndung der Iris bei gleichzeitiger Atrophie ihres Stromas und der Muskulatur. Geringfügige Keratitis und Episcleritis. Bindegewebige Membran auf der vorderen Linsenkapsel, cirkuläre Verwachsung des pupillaren Teiles der Tris mit der ersteren. Beschläge auf der hinteren Hornhautfläche, Degeneration des Hornhautendothels, bindegewebige.Auflagerung auf der Membrana Descemetii; fast völlige Obliteration des Vorderkammerwinkels. Geringgradige, von der Iriswurzel fortgeleitete Entzündung des Ciliarkörpers, Atrophie seiner Muskulatur, sklerotische Verdickung des bindegewebigen Stromas. In der Pars pl. c. cil. Bindegewebsneubildung ùm den Fremdkörper nebst ausgesprochenen Wucherungen der pigmentierten wie unpigmentierten Epithellage. Cataracta traumatica, Proliferation des Kapselepithels. Hochgradige Glaskörperschrumpfung. Chronische proliferative Chorioiditis, stellenweise fibröse Umwandlung des Aderhautstromas, Knochenbildung in der Aderhaut und im Fremdkörperbett. Totale Degeneration der nicht abgelösten Netzhaut und teilweiser Zerfall derselben. Neubildung von endotheläbnlichen Häutchen auf der inneren Netzhautoberfläche. Atrophia n. opt., kesselförmige Excavation der Papille. Glaucoma secundarium. Deutlich ausgesprochene Siderosis der Iris und der Hornhautbeschläge, der Netzhaut und der inneren Epithellage des Ciliarkörpers; weniger stark ausgesprochene Siderosis des Pigmentepithels des Ciliarkörpers und der Retina, des Kapselepithels der Linse und des Pupillenexsudates, sehr stark ausgesprochene im Fremdkörperbett, kaum angedentete in der Cornea und Sklera. 
Der klinische Verlauf des Falles, so auch der mikroskopische Befund machen einen infektiösen Prozess unwahrscheinlich und lassen die Siderosis, so auch die histologischen Veränderungen lediglich anf die Wirkung des Eisensplitters zurückftihren. Die mikroskopische Untersuchung ergab, dass dieser in der Nähe des Hornhautzentrums eingedrungen war, die Linse perforiert hatte und unten in der Pars plana des Ciliarkörpers vor der Ora serrata stecken geblieben war (Taf. XV, Fig. 1 s).

Wie bekannt, unterscheiden die Autoren eine direkte und indirekte Siderosis. Erstere tritt in der Umgebung des Fremdkörpers ein, letztere in den vom Fremdkörper entfernt liegenden Gewebspartien. Die indirekte Siderosis braucht, wie die Untersuchungen v. Hippels(17) gezeigt haben, nicht immer rom Fremdkörper (xenogen) zu stammen, sie kann gleichfalls durch die bei der Verletzung entstandenen Blutungen hervorgerufen werden (hämatogen). v. Hippel(17) hielt eine xenogene Siderosis für Linse und Iris für erwiesen. Hertel hat in einer späteren Arbeit eine solche auch für die übrigen Augenhäute mit Ausnahme der Aderhaut nachgewiesen. Auf Grund meiner Untersuchungen, vor allem des Fehlens ron Hämorrhagien, kann ich mich den Erwägungen Hertels anschliessen und die in meinem Falle rorliegende, recht stark verbreitete Siderosis als eine ausschliesslich xenogene betrachten. Anderseits werden unsere Kenatnisse tiber die Siderosis durch unsern Fall weiter ergänzt. Dieser lehrt betreffs der Regenbogenlaut, dass nicht allein in präexistierenden Gewebszellen das Eisen zu suchen ist, dieses auch in grosser Menge von entzündlichen Produkten, gewissen Granulationszellen, aufgenommen werden kann, letztere ihrerseits in die vordere Kammer treten und an der hinteren Hornhautfläche zur Bildung stark eisenhaltiger Präcipitate tühren können ${ }^{1}$ ). Ferner beweist unser Fall, dass nicht allein das Protoplasma, wie E. v. Hippel(17) amimmt, sondern auch der Kern an der Eisenaufnahme sich beteiligen kann. Dieses habe ich an den fixen Zellen der Iris, seltener an den plasmatischen Granulationszellen

1) Hirschberg erwahnt kurz in einem rou thm klinisch beobachteten Fall, wo ein Eisensplitter in der Netzhaut lag, unter andern Erscheinungen auch das Auftreten gelblicher Punkte an der Hinterfäalie der durchsichtigen Hornlaut. Doch liegt kein Grund vor, diese als Abkömmlinge der Iris bzw. als Präcipitate aufzufassen. Noch früher hat eine ähnliche Beobachtung Landmann gemacht, bei der mikroskopischen Untersuchung erschien aber die Hinterseite ¿er Cornea glatt, die braunen Körnchen waren meist an die fixen Hornhautzellen gebunden und waren hämatogenen Ursprunges. 
Iridochorioiditis serosa nach langjähr. Verweilen eines Eisensplitters usw. 287

einwandsfrei nachweisen können. Diese Zellen lagen fast ausschliesslich in der Omgebung des Sphinkters, ihre Kerne färbten sich diffus blau, während im Protoplasma das Eisen an Körnchen gebunden erschien, mitunter war von einem Protoplasma überhaupt nichts mehr zu sehen. Die genannten Kerne wurden von Kerntarben nicht mehr beeinflusst, die Zellen waren also nekrotisch. Finigemal kamen diese Elemente auch an der hinteren Hornhautfläche zur Beobachtung. Erwähnung bedarf noch der etwas grössere Eisengehalt des Descemetschen Eadothels im Vergleiche zur eigentlichen Hornhautsubstanz und der positive Ausfall der Reaktion seitens des an die hintere Hornhautfläche haftenden feinkörnigen Exsudats. Im übrigen bestätigte die Untersuchung die von den früheren Autoren festgestellten Tatsachen betreffs der Verbreitung und Verteilung des Eisens.

Die histologischen Veränderungen kennzeichneten sich im allgemeinen als proliferative und degenerative. Sie waren bedeutend weiter vorgeschritten als in den vorher veröffentlichten Fällen und traten oftmals unter einem von den früheren Befunden abweichenden Bilde auf. So kam es hier zu einer ausgesprochenen proliferativen Entzündung der Uvea und zu weitgehenden Alterationen des Hornhautendothels: Seitens der Netzhaut beobachtete man ungewöhnliche Wucherungen des Pigmentepithels; inmitten des gliös entarteten Gewebes kam es stellenweise zur Bildung umfangreicher Bindegewebsmassen, anderseits wieder zum völligen Zerfall desselben.

In den Fällen traumatischer seröser Uveitis, so auch in den Beobachtungen von spontan entstandenen serösen Entziindungen, war der vordere Abschnitt der Uvea der am stärksten befallene Teil. Nur im Falle Knies' ersehien auch die Aderhaut erheblich affiziert, bei den friiheren Autoren wies diese Membran entweder gar keine uder sehr schwache Veränderungen auf. In unserm Falle war dagegen der Prozess in der Aderhaut, und hier wieder am hinteren Pol, am weitesten vorgeschritten und am intensivstem ausgesprochen, während in der Iris an den meisten Stellen die entzündlichen Veränderungen noch recht frisch waren. Das überwiegende Ergriffensein der Aderhaut wird von Fuchs(8), Schirmer(37), Ruge(35) u. A. auch bei der sympathisierenden Entzündung hervorgehoben. Fassen wir in unserm Falle die Ureitis als eine traumatische auf, so wird durch ihn das Bild der serösen traumatischen Entzündung erweitert (bekanntlich war in den Fällen Fuchs' die Aderhaut nicht entzündet) und noch mehr der sympathisierenden Entzündung genähert. Auch sonst hatte das pathologisch-bistologische Bild viel Gemeinsames mit dem von Fuchs für 
die sympathisierende Entzündung entworfenen. Die Infiltration der Iris begann in den hinteren Schichten in Form von einzelnen Herden, erst später durchwucherte sie den Sphinkter und erstreckte sich bis zur Irisoberfläche, anderseits zerstörte sie bei weiterem Wachstum nach hinten die retinale Schicht und drang in die retroiritische Schwarte hinein. Im Ciliarkörper erschien das neugebildete Bindegewebe am stärksten entwickelt nach innen vom Muskel und hier wurde auch die diffuse Rundzellenansammlung beobachtet. In der Chorioidea beschränkten sich die jüngeren entzündlichen Herde ausschliesslich auf die Schicht der grossen Gefässe, erst die grösseren durchsetzten die ganze Membran, doch ein Übergreifen des Infiltrats auf die Netzhant kam nirgends zur Beobachtung, die Glasmembran pflegte dem Weiterschreiten des Prozesses Einhalt zu gebieten. Die bindegewebige Umwandlung des Aderhautstromas nahm gleichfalls ihren Anfang in den äusseren Teilen der Membrau, während die Choriocapillaris erst später zugrunde ging. Die Kernvermehrung um die Blutgefässe im Sehnerven, so auch die entzündlichen Veränderungen in der Episklera und den anliegenden Teilen boten nichts Charakteristisches und werden ähnliche Bilder auch sonst bei andem starken Entzindungen des Auges beobachtet.

Beachtenswert erscheinen mir die in grosser Menge in der Iris anzutreffenden und oben näher beschriebenen eigenartigen Zellen. Zum Unterschiede von den einkernigen protoplasmaarmen Rundzellen bezeichnete ich sie als plasmatische Granulationszellen. Die früheren Autoren, soviel mir bekannt ist, lassen sie unerwähnt, nur in einem Falle ron Iridocyclitis serosa traumatica scheint Fuchs ähnliche Zellen beobachtet zu haben, auch ihre Anordnung im Irisstroma entsprach vielfach der in meinem Falle. Diese Zellen erimnerten sehr oft an Unnasche Plasmazellen, als welche sie sich möglicherweise nach entsprechender Fixierung auch erwiesen hätten, da Müllersche Fliissigkeit bekanntlich ihre Darstellung wesentlich beeinträchtigt. Auch das häufige Auftreten von hyalinen Kugeln in diesen Zellen würde zugunsten ihrer Plasmazellennatur sprechen, da nach Unna(40) diese Gebilde nur in Plasmazellen entstehen sollen. Beziehentlich der Abstammung dieser Zellen erscheinen die Anschauungen der Autoren geteilt, während einige mit v. Marschalkó an der Spitze sie von den Lymphocyten des Blutes ableiten, sprechen sich andere gewiegte Forscher, wie z. B. Unna(39), Pappenheim (31) für ihre histiogene Abkunft aus. Ob sämtliche Zellen bindegewebiger Herkunft Plasmazellen zu produzieren im stande sind oder diese Fähigkeit nur gewissen 
Zellen zukommt, darüber sind auch die Autoren des zweiten Lagers nicht einig. Die in unserm Falle in Frage kommenden Zellen schienen in Beziehungen zu den fixen Stromazellen der Tris zu stehen, als deren Abkömmlinge ich sie auch betrachte. Es konnten die allermöglichsten Übergangsformen zwischen beiden Zellarten verfolgt werden, viele dieser neugebildeten Zellen zeigten noch einen wohlausgebildeten Fortsatz, auch lagen letztere mit Vorliebe an Stellen, wo normaliter die Zahl der fixen Zellen vermehrt ist, so an der vorderen. Fläche der Iris und entlang der Gefässe. Ferner zeichneten sich die beiden Zellarten durch ein ähnliches Verhalten dem Eisen gegenüber aus, auch schienen sie in ähnlicher Weise zu degenerieren. Während die plasmatischen Zellen in grossen Mengen in die vordere Kammer abgesetzt wurden und hier den Hauptbestandteil der Präcipitate ausmachten, kam der aus einkernigen Rundzellen bestehenden Infiltration die Eigenschaft zu, sich zu organisieren und Bindegewebe zu liefern.

Die in der Pupillengegend befindliche Membran zeigte ein verschiedenes Aussehen, während der der Linse zunächst liegende Teil schwartenartige Beschaffenheit hatte, wurde näher zur Iris das Gewebe allmählich zellenreicher, stellenweise kennzeichnete es sich als ein gefässreiches Granulationsgewebe. Ein ähnliches Abwechseln, bald jüngeren, bald älteren Granulationsgewebes untereinander sahen wir noch deutlicher ausgeprägt in der Iris und der Aderhaut. Ein solches Bild ist charakteristisch für die chronische rezidivierende Entzündung und findet klinisch seinen Ausdruck in den häufig sich wiederholenden Anfällen.

Die rezidivierende Iritis führte zu vollständigem Abschluss der vorderen Kammer von der hinteren, wonach sich sekundäres Glaukom ausbildete. Die Obliteration des Vorderkammerwinkels, so auch die Sehnervenexcavation resultieren aus der Druckerhöhung. Die gleichzeitig mit der Entzündung anzutreffende Atrophie der Iris wird nur zum Teil aufs Glaukom zuriickzuführen sein und wahrscheinlich bereits vor diesem bestanden haben. In den einschlägigen Fällen wird überall von Atrophie der Iris berichtet, die die Autoren auf die Eisenwirkung beziehen. Auf dem Boden der atrophischen Iris entwickelte sich meines Erachtens erst später die erwähnte Entzündung.

Es wäre erwünscht, künftighin in Fällen, wo nach aseptisch ins Augeninnere eingedrungenen Eisensplittern sich später Entziindung einstellte, den Charakter der letzteren genauer festzustellen. Es ist nicht ausgeschlossen, dass diese sich als eine rornehmlich proliferative erweisen würde. Die im Falle v. Hippels (18) verhältnismässig geringe 
und im Falle Ruges (Beob. XLVIII) stärker ausgesprochene, teils herdförmige, teils diffuse Infiltration vou einkernigen Rundzellen in der Uvea beim Fehlen jeglicher Exsudatbildung sind Befunde, die den Anfangsstadien einer chronischen proliferativen Iridochorioiditis entsprechen. Auch sei hier der Tierversuche Erdmanns gedacht, der durch Einführen elektrolytisch dargestellten Eisens in die Kammer eine proliferierende Entziundung im Filterwerk des Kammerwinkels und proliferative Veränderungen seitens des Hornhautendothels hervorrufen konnte.

Wie die Untersuchmingen Lebers lehren, kann die Wirkung chemischer Substanzen auf das Zellprotoplasma entweder eine reizende oder eine tötende sein, wobei es wie auf die Konzentration der Substanz, so auch auf diese als solche ankommt. Beziehentich der Wipkung des Eisens auf das menschliche Auge zeigen uns die Befunde, dass diese vornehmlich eine reizende zu sein pflegt, indem dieses Metall gewisse Gewebe (Pigmentepithel der Retina, Kapselepithel der Linse, Neuroglia der Netzhaut) zur Proliferation anregt. Auch die entzündlichen Veränderungen in der Crea, die in meinem Falle sich vornehmlich als Wuchertugen der präexistierenden Gewebszellen doknmentierten, sind meines Erachtens ihrem Wesen uach den in der Retina und in der Linse zu beobachtenden Proliferationserscheinungen gleichzustellen. Die Verschiedenheit des Bildes findet ihre Erklärung in der verschiedenen Herkunft der wuchernden Elemente and in der Eigenartigkeit der affizierten Membran.

Dass die Veränderungen in unserm Falle so weit gediehen warei, lässt sich teils durch die lange audanernde Eisenwirkung erklären, teils auf die wnvollständige bindegewebige Einkapselung des Fremdkörpers zuriickführen, wodurch die Diffusion der gelösten Eisenteilchen begünstigt wurde [r. Hippel(18)]. Beachtenswert in unserm Falle erscheint die vollständige Verrostung des Fremdkörpers und die successive Auflösuxg des Rostes. Ein vollständiges Verrosten behauptet Hirschberg in seinen zahlreichen Fällen nie beobachtet zu haben, spätere Autoren haben solches doch angenommen, durch die Befunde vou Gilbert(9), Pihl(32) u. A. hat eine solche Vermutung Stutze gewonnen, durch meinen Fall zur Tatsache geworden.

Ferner bringt unser Fall gewisses Licht in die Frage über die Herkunft der Präcipitate. Knies hat bekanntlich als erster genau und ausführlich einen Fall voll Iritis serosa mikroskopisch untersucht. Fr sprach sich aus, dass die Zellen an der hinteren Hornhautläche mindestens zum grössten Teil aus der Iris stammen müssten. Diese 
Ansicht fand sofort lebhaften Widerspruch bei Arlt, der behauptete, dass die Beschläge rom Ciliarkörper herrührten und aus der hinteren Kammer kämen. Nachher hat Fuchs(7) die Meinung Arlts durch Untersuchungen an Augen mit Iritis syphilitica wesentlich gestützt. Auch die Befunde Ridleys sprechen zugunsten der Annahme Arlts. Die späteren Untersuchungen von Groenouw (13), Harms(14) u. A. haben eine Beteiligung der Iris an der Produktion der Präcipitate wieder wahrscheinlich gemacht. Den sicheren Beweis dafür lieferte aber erst Baas durch die Untersuchung eines Falles von Iritis mit Beschlägen auf der hinteren Hornhautfläche. Es bestand zugleich Seclusio pupillae und ein Durchtreten von Exsudation aus dem Ciliarkörper durch die Triswurzel war nicht zu erkennen. Wie aus der leider an einigen Stellen kurz ausgefallenen Beschreibung ersichtlich ist, hat auch eine Fntzündung der übrigen Membranen bestanden, vor allem eine stark entzindliche Infiltration des Ciliarkörpers. Dieser erschien in eine Bindegewebsmasse eingebettet, die durch Schrumpfung zur Verkleinerung des Bulbus geführt hatte. Wie die klinische Beobachtung, insbesondere aber der histologische Befund zeigte, treffen die von Baas gemachten Erwägungen auch für meinen Fall zu und dieser bestätigt von neuem aufs beste, dass mitunter die Präcipitate einzig von der Iris stammen können. Ferner lehrt aber unser Fall, dass bei der Iridochorioiditis serosa, bei welcher die intensivsten entzündlichen Erscheimungen im Ciliarkörper zu erwarten wären, unter Umständen im letzteren sehr gering sein oder fast fehlen können. Die innere Oberfläche des Ciliarkörpers war überall frei, einem Durchtritte von Zellelementen ins Augeninnere stand nichts im Wege, doch konnte nirgends ein solcher vermerkt werden, auch die hintere Irisfläche war frei von Präcipitaten. Also bedarf die auch heute noch vielfach verbreitete Deutung der Präcipitate als Charakteristikum einer Cyclitis eine gewisse Einschränkung, da diese einzig allein von der Iris gebildet werden können bei fast pölligem Fehlen entzündlicher Erscheinungen seitens des Ciliarkörpers und bei Abwesenheit jeglicher Anzeichen ron Durchtritt zelliger Elemente auf dessen Oberfläche.

Was die Veränderungen des Hornhautendothels betrifft, so lenkt von diesen eine besondere Aufmerksamkeit auf sich die in der Nähe des Kammerwinkels gelegene bindegewebige A uflagerung. Ahnliche Bildungen sind schon bei andern Erkrankungen des Auges zu wiederholten Malen beschrieben worden, so auch bei der Iritis serosa (Bartels, Harms). Fuchs(8) lässt das neugebildete Bindegewebe aus den Exsudatzellen hervorgehen, welcher Meinung ich auf Grund 
meines Befundes doch nicht beipflichten kann. Die in die Vorderkammer geratenen Zellen zeigten in meinem Falle meist Degenerationserscheinungen und schienen nicht von langer Lebensdauer zu sein, anderseits fiel es gar nicht schwer, die Entstehung des Gewebes vom Endothel zu verfolgen. Auf die Bildung eines solchen ,endothelogenen Bindegewebes" vom Endothel der Hornhant hat zuerst Wagenmann (43) hingewiesen und hat diese Ansicht in späteren Arbeiten vielfach ihre Bestätigung erfahren. Ferner hat Wagenmann(43) gezeigt, dass das Endothel eine glasige homogene Substanz liefern kann, mein Fall, so auch meine früheren Cntersuchungen (34) dienen nur zu einem neuen Beleg für die Richtigkeit dieser Auffassung. Wucherungen des Descemetschen Endothels hat auch Leber in seinen Tierexperimenten nach Einführung fein verteilter schwer löslicher Substanzen in die Vorderkammer, wie Gold, Zinnober, Kieselsäure usw. beobachten können. In letzter Zeit hat, wie schon oben mitgeteilt wurde, Erdmanu auch nach Einfübrung von Eisen ähnliche Wucherungsprozesse an den Endothelien der Hornhaut gesehen und sie auf die Eisenwirkung zurïickgeführt. Das mikroskopische Bild war dem in meinem Falle ähnlich. Leber hat zur Geniige dargetan, dass die Gewebsveränderung nicht auf mechanische Einftüsse, sondern auf die chemische Wirkung der Substanzen bezogen werden muss. Tch stehe nicht an, die Wucherung des Endothels aut gleiche Stufe mit der Proliferation des Kapsel- oder Pigmentepithels zu stellen, und für diese wird ron allen Autoren das Eisen doch als schuldig erklärt. Nach dem Gesagten erlaube ich mir, auch in meinem Falle die Wucherung des Endothels an der hinteren Hornhautfläche auf die chemische Wirkung des Eisens zurückzuführen.

Die Veränderungen in der Netzhaut stimmen vielfach mit den trüher in einschlägigen Fällen beschriebenen iäberein, nur erscheinen sie in meinem Falle viel weiter vorgeschritten. Ausser einer hockgradigen Gliose nebst völligem Schwunde nerröser Elemente kam es in der Retina zu stark ausgesprochener Bindegewebsbilding, stellenweise wieder zu weitgehender Nekrose des gewucherten Gliagewebes. Diese Veränderungen liessen sich ganz gut mit den Ergebnissen des Tierexperimentes, so auch den Befunden an menschlichen Augen in Einklang bringen und würden auf die Wirkung des Eisens zu beziehen sein. Es ist nicht ausgeschlossen, dass auch die erheblich alterierte Aderhaut zu der schweren Schädigung der Retina beigetragen haben wird, wie das nach den Arbeiten Wagenmanns (43 u. a.) anzunehmen ist. Ganz evident trat die Relation der Aderhauterkrankwung 
Iridochorioiditis serosa nach langjäh. Verweilen eines Eisensplitters usw. 293

zur Netzhaut im Falle Linkes zutage. Auch die Drucksteigerung wird ihren Einfluss auf die Netzhaut ausgeübt haben müssen.

Erwähnung bedürfen noch die auf der inneren Netzhautoberfläche anzutreffenden endothelartigen Zellen und kugligen Gebilde. Über das Vorkommen von Zellhäutchen auf der Innenfläche der Retina liegen in der Literatur bereits Mitteilungen vor, so haben unter andern schon Iwanow bei chronischer Retinitis, Herzog Karl bei Glaskörperablösung ähnliche Zellen beschrieben. Die neneren Autoren [Groenouw (12), Ginsberg(11)] sind geneigt, letztere von den Endothelien und andern Zellen des Bindegewebes der Netzhautgefässe abzuleiten. Neulich hat sich Krüickmann (24) ansgesprochen, dass auch Gliazellen unter Umständen ein epithelartiges Aussehen erhalten können. In meinem Falle kann ich mich weder der einen, noch der andern Meinung anschliessen, am bequemsten erscheint es mir, die Zellen rom Pigmentepithel abzuleiten, wofür folgende Tatsachen sprechen würden: 1. Die grosse Ähnlichkeit der genannten Zellen mit den Epithelien, die das Fremdkörperbett vom inneren Augenraum begrenzen. 2. Das Überwuchern des Pigmentepithels auf die Ora serrata und von hior auf die immere Netzhautoberfläche. 3. Die auf der inneren Bulbusoberfläche massenhaften kugligen Gebilde. Diese konnten sowohl vom Pigmentepithel, wie von den erwähnten endothelähnlichen Zellen abgeleitet werden, andere Elemente beteiligten sich an ihrer Produktion nicht.

Den Vorgang bei der Entstehung der Zellmembran stelle ich mir in folgender Weise vor. Durch die Eisenwirkung zur Wucherung angeregt, kleideten die Epithelien allmählich den hinteren Augenraum aus. Später verfielen letztere ähnlich der unterliegenden Netzhaut der Degeneration and Nekrose. Wie für die Netzhaut, so auch für das Zellhäutchen schienen die Lebensbedingungen am günstigsten sich noch in der Nähe des hinteren Augenpoles entfernt rom Fremdkörper zu gestalten, an welcher Stelle die Membran ihre zelligen Bestandteile noch erkennen liess, sonst waren gewöhnlich nur ihre Degenerationsprodukte, die kugligen Gebilde zu sehen.

Fasse ich kurz die wichtigsten Ergebnisse meiner Untersuchung zusammen, so lassen sich folgende Sätze aufstellen:

1. Die Iridochorioiditis serosa chronica kann durch einen ins Augeninnere aseptisch eingedrungenen Eisensplitter hervorgerufen werden.

2. Der Iridochorioiditis serosa chronica entspricht ein charakte- 
ristisches histologisches Bild und dieses stellt im pathologisch-anatomischen Sinne eine chronische proliferierende Entziindung der Uvea dar.

3. Die bei seröser Uveitis an der hinteren Hornhautwand anzutreffenden Beschläge können einzig und allein von der Iris stammen und dürfen sie bei gleichzeitiger Iritis nicht als Symptom einer Cyclitis aufgefasst werden.

4. Infolge ron Eisenwirkung kann das Descemetsche Endothel in Wucherung geraten und zu bindegewebigen Auflagerungen auf der hinteren Hornhautflüche fiuhren.

5. Die in seltenen Fallen auf der imneren Oberfläche der Netzhaut anzutreffenden endothelähnlichen Zellen können :zuweilen rom Pigmentepithel stammen.

Zum Schluss ist es mir eine angenehme Pticht, Herrn Professor W. v. Wyssokowitsch für seine mehrfachen treundlichen Ratschläge meinen aufrichtigen Dank auszusprechen.

\section{Literaturverzeichnis.}

1) Arlt. Ber. über d. 12. Vers. d. ophth. Ges. z. Heidelberg. 1879. Diskuss. zum Vortrag v. Knies.

2) Baas, Uber Iritis serosa. Zeitschr. f. Augenheilk. Bd. IX. 1903.

3) Bartels, Über Neubildung von Bindegewebe an der Hinterfläche der Hornhaut. Klin. Monatsbl, $f$ Augenheilk. Juli 1905.

4) Bunge, Über Siderosis bulbi. Verh. d. X. intern. med. Kongr. Bd. IV. S. $151-154$. Berlin 1891.

5) Cramer, Beiträge zu dem klinischen Verhalten intraokularer Eisensplitter. Zeitschr. f. Augenheilk. Bd. II. 1899.

6) Erdmann, Über experimentelles Glaukom nebst Untersuchungen an glaukomatösen Tieraugen. $v$. Graef e's Arch. f. Ophth. Bd. IXXVI. 1907.

7) Fuchs, Anatomische Miszellen. V. Graefe's Arch. f. Ophth. Bd. XXX, 3 . S. $125-156.1884$.

8) - Über sympathisierende Entzündung (nebst Bemerkungen über seröse traumatische Iritis). v. Graefe's Arch. f, Ophth. Bd. LXI, 2. 1905.

9) Gilbert, Über Pigmentschwund pigmentierter Beschläge im Verlaufe von Iritis. Klin. Monatsbl, f. Augenheilk. Juli-Aug. 1906.

10) - Klinische und pathologisch-anatomische Beiträge zur Kenntnis:degenerativer Hornhauterkrankungen. v. Graefe's Arch. f. Ophth. Bd. LXIX, 1. 1908.

11) Ginsberg, Grundriss der pathologischen Histologie des Auges. Berlin 1908.

12) Groenouw, Ein Fall von unpigmentiertem alveolärem Flächensarkom des Ciliarkörpers, nebst Bemerkungen uber das Vorkommen epitheloider Zellen in und auf der Retina bei Glaukom. v. Graefe's Arch. f. Ophth. Bd. XLVII, 2. 1899 .

13) - Anatomische Untersuchungen über Iridocyclitis serosa. Klin. Monatsbl. f. Augenheilk. 1900. S. 186-226.

14) Harms, Zur pathologischen Anatomie der Iridocyclitis mit Beschlägen auf der hinteren Hornhautwand. Klin. Monatsbl. f. Augenheilk. Juli-Aug. 1904.

15) Hertel, Anatomische Untersuchung eines Falles von Siderosis bulbi. v. Graefe's Arch. f. Ophth. Bd. XLIV, 2. 1897.

16) Herzog Karl, Beiträge zur Anatomie und Pathologie des Claskörpers. v. Graefe's Arch. f. Ophth. Bd. XXV, 3. 1879. 
Iridochorioiditis serosa nach langjähr. Verweilen eines Eisensplitters usw. 295

17) Hippel. E. v., Über Siderosis bulbi und die Beziehungen zwischen siderotischer und hämatogener Pigmentierung. v. Graefe's Arch. f. Ophth. Bd. XL, 1. 1894.

18) - Über Netzhautaegeneration durch Eisensplitter. v. Graefe's Arch. f. Ophth. Bd. XLII, 4. 1896.

19) Hirschberg, Über die Ergebnisse der Magnetoperation in der Augenheilkunde, v. Graefe's Arch. f. Ophth. Bd. XXXVI, 3.

20) Horn, Ein Fall won Siderosis bulbi mit pathologisch-anatomischem Befund. Inaug.-Diss, Giessen 1906.

21) I wanow, Beiträge zur normalen und pathologischen Anatomie des Auges. v. Graefe's Arch. f. Ophth. Bd. XI, 1. 1865.

22) Knies, Iritis serosa nebst Bemerkungen über sympathische Übertragung. Arch. f. Augenheilk. Bd. IX. S. 1-27. 1879. Ber. über d. 12. Vers. d. ophth. Ges. zu Heidelberg. 1879.

23) Krü clkmann, Die pathologischen Veränderungen der retinalen Pigmentepithelzellen. v. Graefe's Arch. f. Ophth. Bd. XUYIII, 2. 1899.

24) - Über Pigmentierung und Wucherung der Netzhautneuroglia. v. Graefe's Areb. f. Ophth. Bd. LX, 3. 1905.

25) Landmann, Über die Wirkung aseptisch in das Auge eingedrungener Fremdkörper. v. Graefe's Arch. f. Ophth. Bd. XXVIII, 2.

26) Leber, Th., Die Entstehung der Entzündung. Leipzig 1891.

27) Lincke, Über das dreissigjährige Verweilen eines Eisensplitters im Auge mit anatomischem Befund. Inaug.-Diss. Jena 1903.

28) Marschalkó, v., Über die sog. Plasmazellen. Arch, f. Dermat. u. Syphil. Bd. XXX. 1895.

29) Natanson. Ber. über d. 31. Vers. d. ophth. Ges. in Heidelberg. 1903.

30) Panas, Traité des maladies des yeux. I. 1894.

31) Pappenheim, Weitere kritische Ausführungen zum gegenwärtigen Stand der Plasmazellenfrage. Virchow s Arch. Bd. CLXIX, 3. 1902.

32) Pihl, Kasuistischer Beitrag zur sympathischen Ophthalmie, nebst einigen pathologisch-anatomischen Untersuchungen, . Graefe's Arch. f. Ophth. Bd. LX, 3. 1905.

33) Ridley, Serous cyclitis. The Royal London Ophth. Hospital Reports. Vol. XIV, 1. Ref. Zentralbl. f. Augenheilk. Bd. XX. S. 344. 1896.

34) Rubert, Zur hyalinen Degeneration der Hornhaut. Arch. f. Augenheilk. Bd. LXV. 1910.

35) Ruge, Pathologisch-anatomische Cntersuchungen über sympathische Ophthalmie und deren Beziehung zu den übrigen traumatischen und nicht traumatischen Uveitiden. v. Graefe's Arch. f. Ophth. Bd. LVII. 1908.

36) Schirmer, Über Siderosis bulbi. Münchn. med. Wochensehr. 1898. S. 408.

37) - Symp. Augenerkrankung. Graefe-Saemis ch, Handb. Lief, 23-25. 1900.

38) Sehweigger. Handb. d. Augenheilk. 5. Anfl. S. 333. 1885.

39) Unna, Uber Plasmazellen, insbesondere beim Lupus. Monatshefte f. prakt. Dermat. Bd. XII. 1891.

40) - Atlas 2. Pathol. d. Hant. Heft 6-7. S. 170.1903.

41) Uhthoff, Zur Siderosis retinae et bulbi. Deutsche med. Wochensehr. Nr. 48 it. 49.1903.

42) Vossius, Siderosis bulbi. Encykl. d. Augenheilk. Lief. 17. 1909.

43) Wagenmann, Experimentelle Untersuchungen über den Einfiuss der Cirkulation in den Netzhant- und Aderhautgefässen auf die Emährung des Anges. v. Graefe's Arch. f. Ophth. Bd. XXXVI, 4. 1890.

44) - Weitere Mitteilungen über glashäntige Neubildungen an der Descemet schen Membran und auf der Iris und über Veränderungen des Hornhautendothels. v. Graefe's Arch. f. Ophth. Bd. XXXVIII, 2. 1892.

45) Watanabe, Anatomische Untersuchungen von 4 Augen mit traumatischer Iridocyel. Klin. Monatsbl. f. Augenheilk. Aug. 1910. 
Erklärung der Abbildungen auf Taf. XV u. XVI, Fig. 1-4.

Fig. 1. Vorderer Abschnitt des Bulbus. Der Schnitt liegt in der Nähe des Pupillarrandes. An der hinteren Hornhantfläche sieht man inmitten einer diffus angedeuteten Eiweissmasse einzelne Präcipitate $p$. Der Vorderkammerwinkel ist oben verlegt, die Iris oben dünner als unten. $h$ entzündliche Herde der Iris hinter dem Sphinkter sph gelegen, der grösste Herd $g h$ reicht bis zur Irisvorderfläche, nach hinten hat er die retinale Schicht zerstort und dringt in die retroiritische Schwarte $m$ ein. Bei $w$ wuchert das Pigmentepithel in die Tiefe. Ein kleiner. Herd $k h$ an der vorderen Oberflsche der Iris. $h$ Linsenreste, $i$ entzündliche Infiltration in der Episklera. $g l$ abgelöster Glaskörper. $f$ Frendkörperbett mit Residven des Eisenfragments s. Der Ciliarkörper und die Aderhaut sind leicht abgehoben, die Suprachorioidea ausgedehnt infolge der Härtung. ah entzindlicher Herd in der Aderhaut. Farbung mit Hämatoxylin-Eosin. Lupenvergrösserung.

Fig. 2. Austreten von Exsudatzellen aus der entzündeten Iris in die Vorderkammer und Entstehung von Beschlägen an der hinteren Hornhautflüche. $c$ Hornhant. d Descemetsche Membran. ez Exsudatzellen aus der Iris, vielfach Pigment pi enthaltend. en degenerierte Endothelien. Die vordere Flache der Iris ist nicht streng begrenzt und erseheint einer granulierenden. Wunde ähnlich. Die Entzündung hat hier einen diffusen Charakter, bloss um ein Gefäss tritt sie mehr herdförmig $h$ auf, die Zellen sind hier schon bei schwacher Vergrösserung als einkernige Rundzellen kenntlich, an den übrigen Stellen lassen die Zellen einen deutlichen Protoplasmaleib erkennen, bei zw haben die Zellen die Gefässwand durchwuchert und erfullen zum Teil das Lumen. An der Vordertäche der Iris grobkörniges Pigment $\hat{m}$, der hinteren Irisfläche liegt, wie bei der Hornhaut, eine feinkornige Masse em an, zellige Elemente fehlen hier jedoch. we im Überwandern befindliche Zellen. Färbung mit Hämatoxylin-Eosin. Reichert 0k. 3, Obj. $4 \mathrm{~b}$.

Fig. 3. Kapselstarähnliche Bindegewebsauflagerung $b$ auf der hinteren Hornhautfläche mit den Lamellen des Ligamentum pectinatum $7 p$ zusammenhängend. Die Maschen des Ligamentum pectinatum sind von Exsudatzellen $e z$ vollgepfropft. Iris entzündet wie in Fig. 2. Färbung mit Hämatoxylin-van Gies on. Reichert Okn 3 , Obj. $4 \mathrm{~b}$.

Fig. 4. Präparat aus dem hinteren Bulbusabschnitt. Die Retina $R$ erscheint in ein netzlormiges, an Stelle der ehemaligen Nervenfaserschicht $n$ in ein faseriges Gliagewebe umgewandelt. Von der Netzhautschicht sieht man nur noch Andeutungen in Form von stellenweise zusammenliegenden Körnern $k$. Auf der inneren Oberfläche endothelartige Zellen $e$ in kuglige Gebilde $\mathrm{kg}$ übergehend. $p i$ Pigmentwucherung. Ein in hyaline Masse umgewandeltes Gefäss $g$ konfluiert mit einem aus dem Pigmentepithel entstandenen drusigen Gebilde $d$. Membrana limitans ext. me, vielfach durchwuchert. pe Pigmentepithel, zum Teil desquamiert $p d$ in subretinale Räumchen $s *$. $k n$ Knochenbildung. $v$ Glaslamelle. Die Aderhatut $C h$ zeigt bindegewebige Unwandlung, die Choriocapillaris ist obliteriert. Das Stromapigment $s p i$ ist gewuchert; findet sich auch inmitten eines in einen bindegewebigen Strang verwandelten Gefässes vor. $S$ Sklera. Färbung mit Hämatoxylin-Eosin. Reichert Ok. 3, Obj. 4 b.

Die Zeichnungen sind von Herrn stud. med. M. Marenin angefertigt worden, wofür ich ihm meinen verbindlichsten Dank ausspreche. 


$$
8
$$




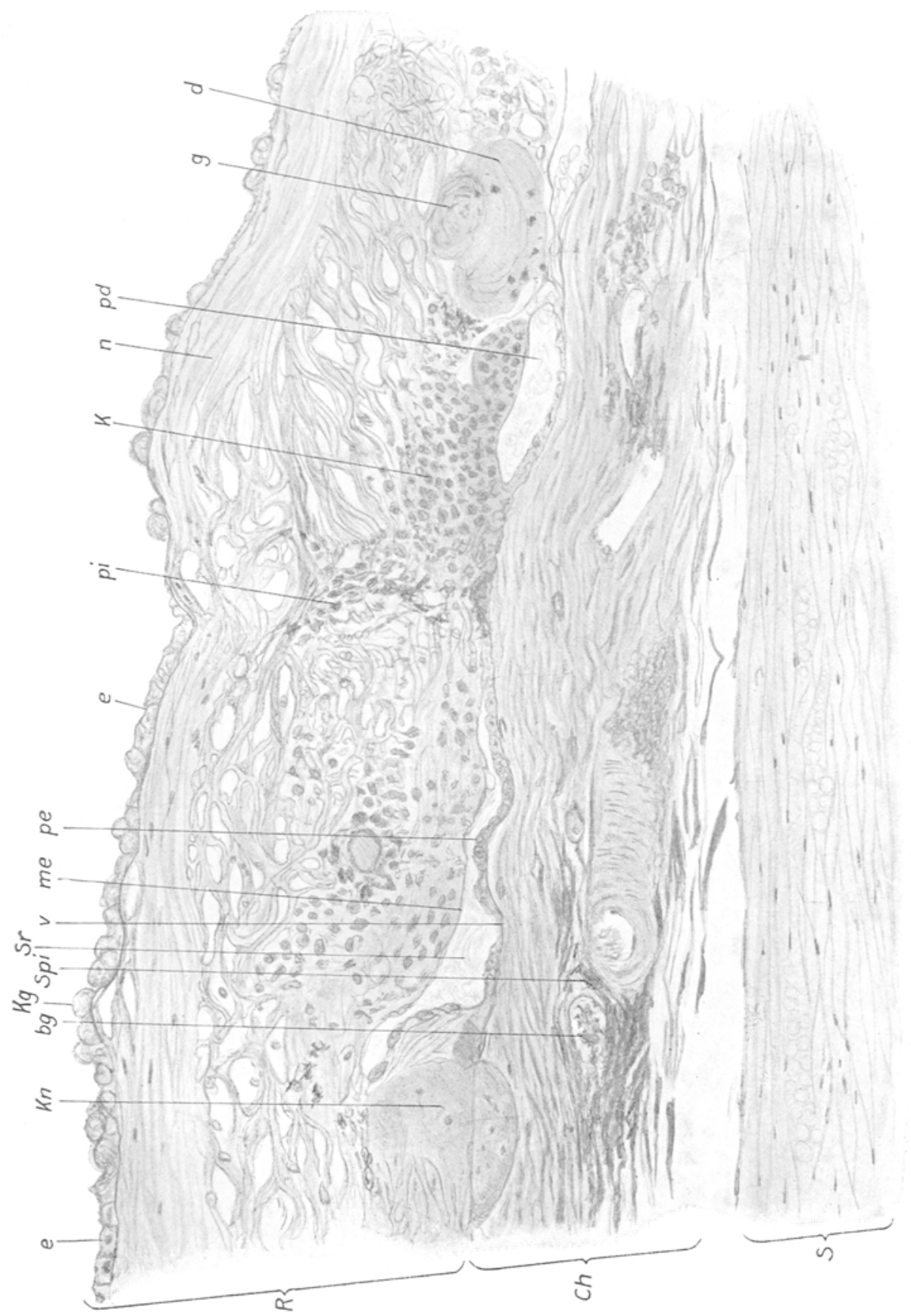

Fig, 4. 